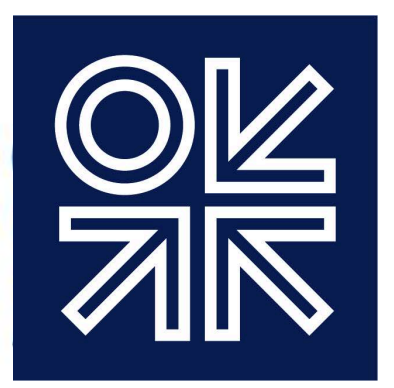

THE OXFORD

INSTITUTE

FOR ENERGY

STUDIES

September 2017

\title{
Fiscal policy for decarbonisation of energy in Europe
}

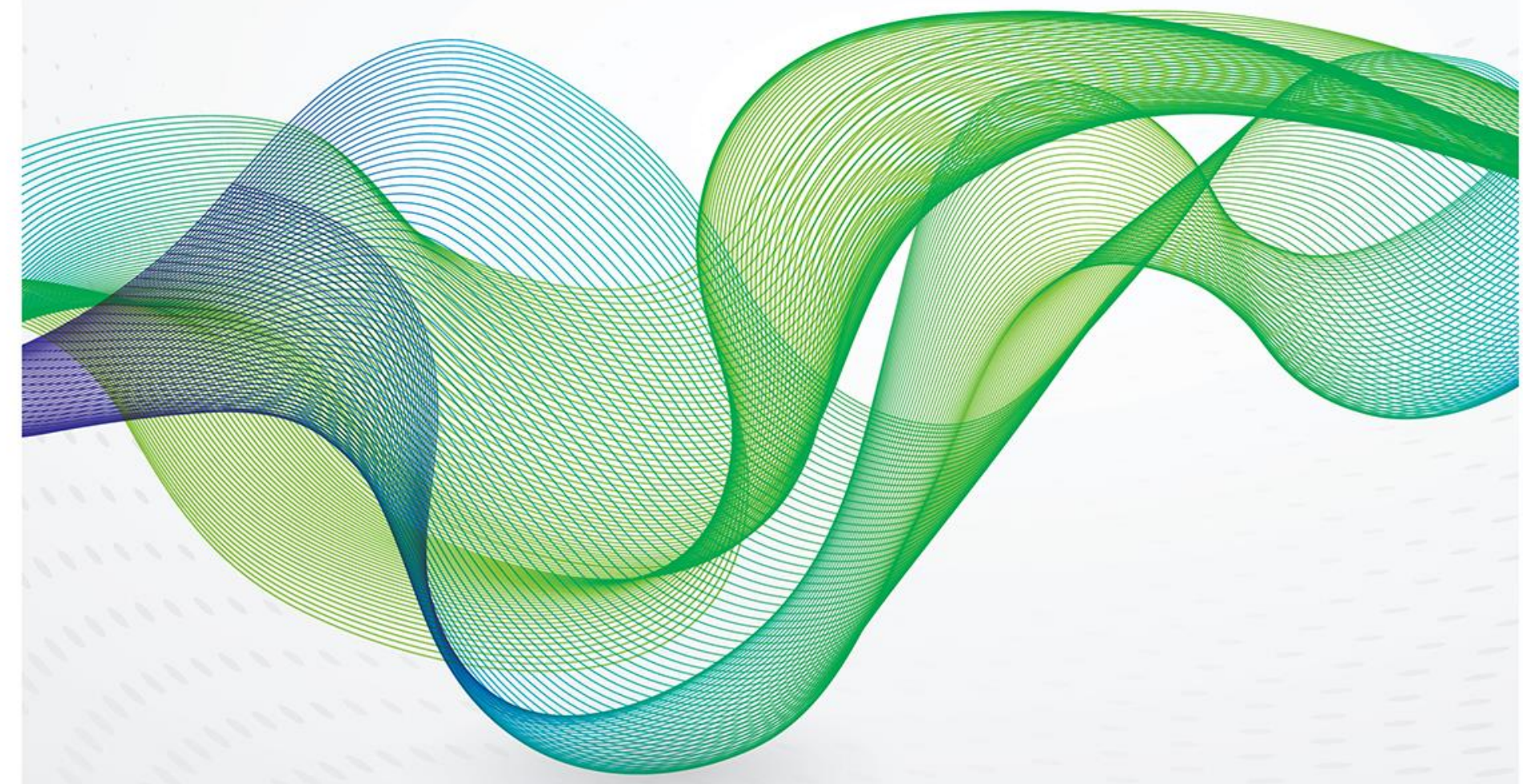


The contents of this paper are the authors' sole responsibility. They do not necessarily represent the views of the Oxford Institute for Energy Studies or any of its members.

Copyright $\odot 2017$

Oxford Institute for Energy Studies

(Registered Charity, No. 286084)

This publication may be reproduced in part for educational or non-profit purposes without special permission from the copyright holder, provided acknowledgment of the source is made. No use of this publication may be made for resale or for any other commercial purpose whatsoever without prior permission in writing from the Oxford Institute for Energy Studies.

ISBN 978-1-78467-092-4 


\section{Contents}

1. Introduction

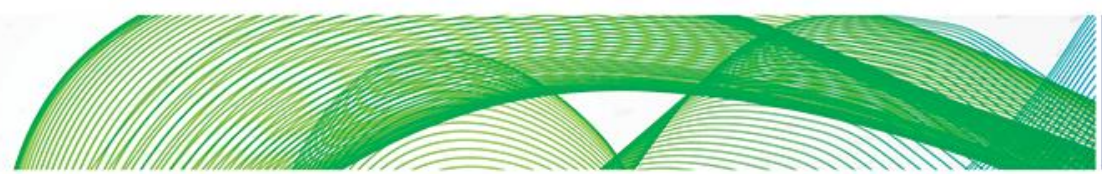

2. Electricity and the consensus view

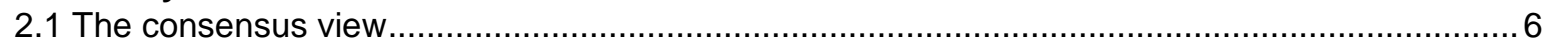

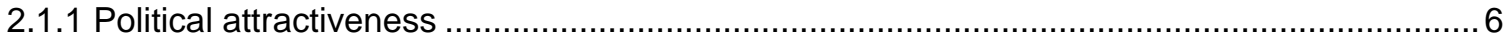

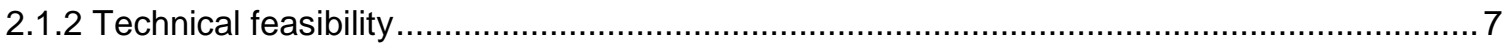

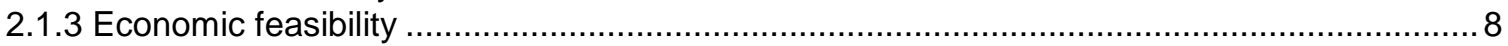

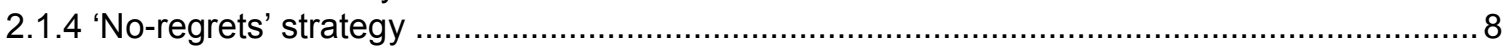

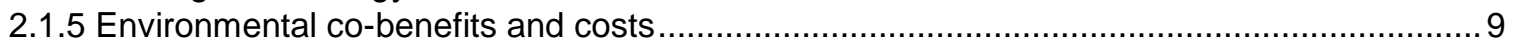

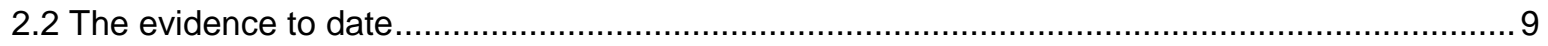

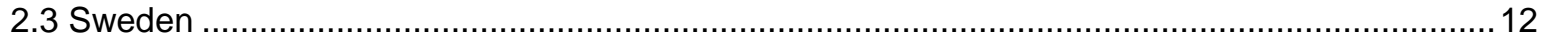

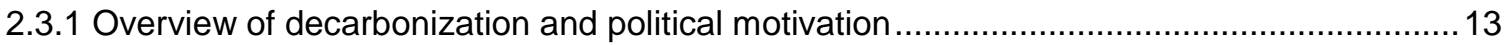

2.3.2 Fiscal policy to support decarbonization of heat and transport ......................................... 14

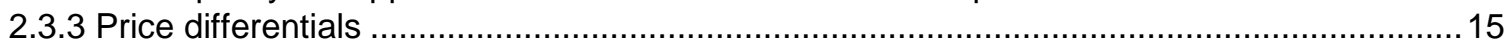

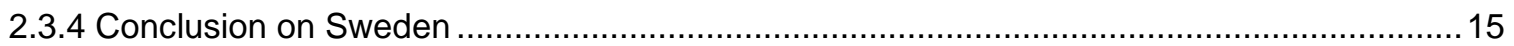

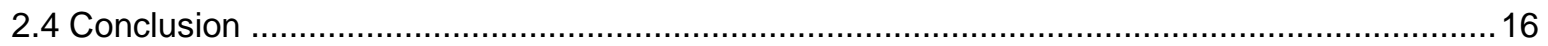

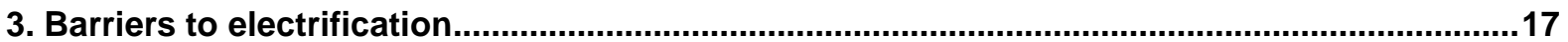

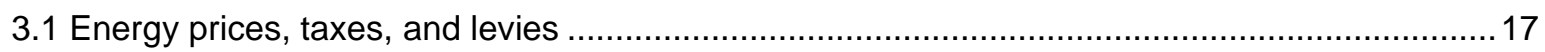

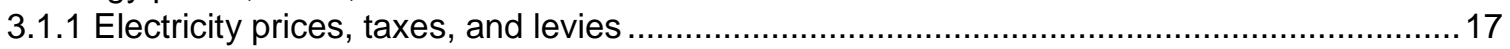

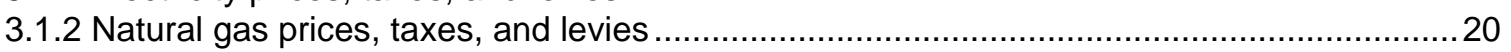

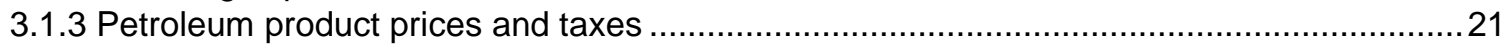

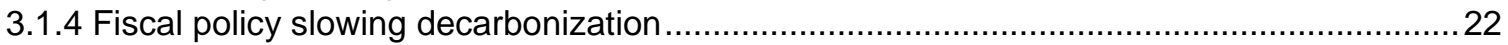

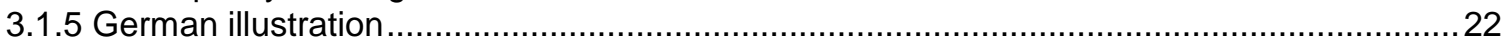

3.2 The UK case of decarbonization of heat - electrification versus greening gas ........................23

3.2.1 The choice between electrification and the greening of gas ............................................23

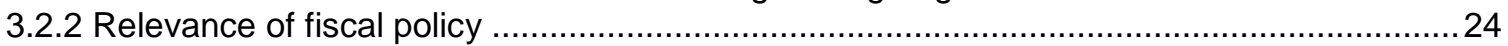

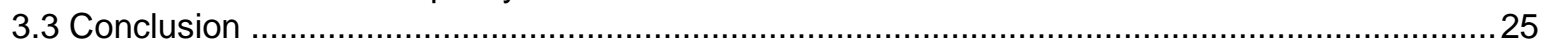

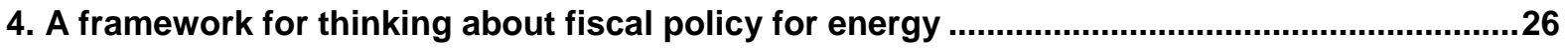

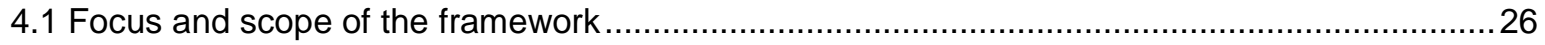

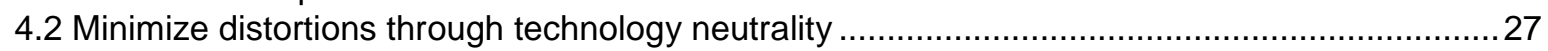

4.3 Tax negative environmental externalities (Pigouvian taxes) .............................................. 27

4.3.1 Economy-wide taxation of air pollution and other externalities .......................................2

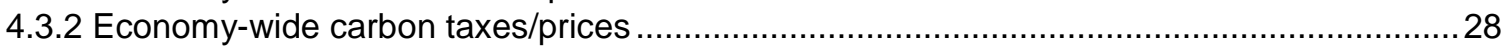

4.4 Finance renewables and other public goods through general taxation ......................................

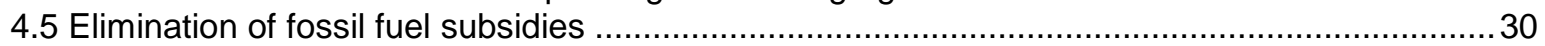

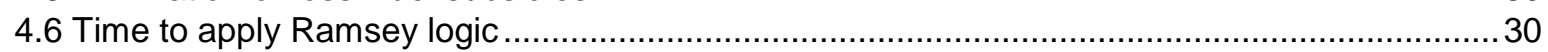

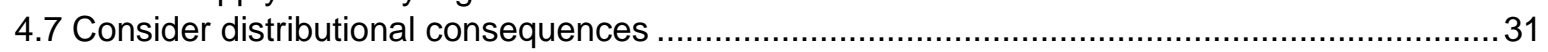

4.8 Recover levies and system costs in a way that minimizes distortion of electricity markets ........31

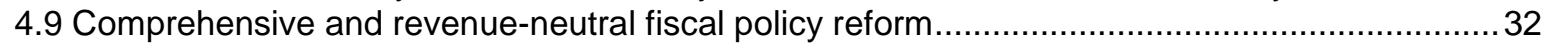

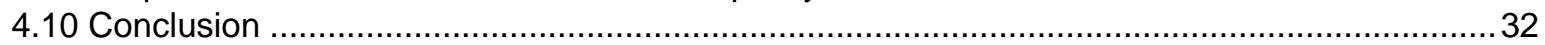

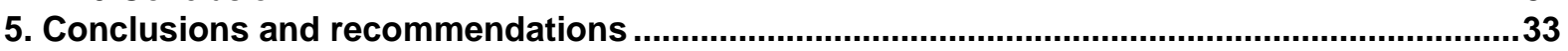

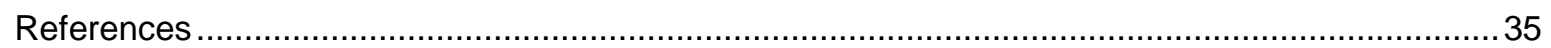

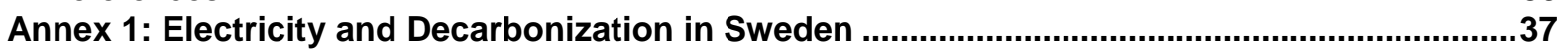

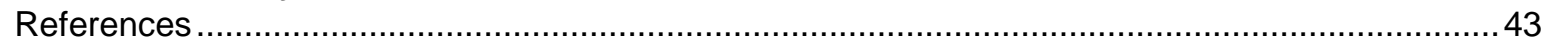

Annex 2: Decarbonization of heat in the UK and the role of 'green gas' - can economic

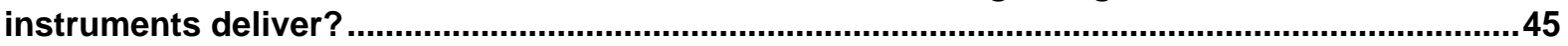

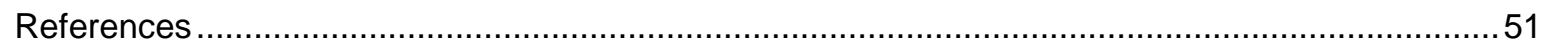




\section{Figures}

Figure 1: Total EU-28 CHG Emissions excluding LULUCF, 1990-2014 (ktC02 eq.)..........................10

Figure 2: GHG Emissions by sources EU-28, 1990-2014 ......................................................11

Figure 3: EU Power generation 2010-16 (TWh) …................................................................. 12

Figure 4: Total energy use in Sweden by energy carrier (1970-2016) .......................................13

Figure 5: GHG emissions in Sweden from heating of dwellings and services 1990-2015 with vertical

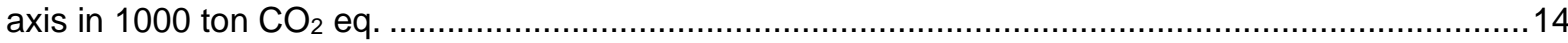

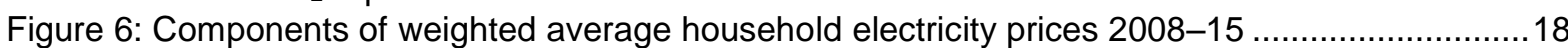

Figure 7: National electricity retail prices for households in the EU in 2015................................18

Figure 8: Share of the sub-components (weighted EU average) for taxes and levies in household

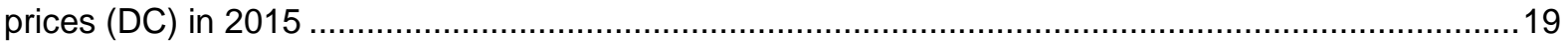

Figure 9: Components of average EU household retail natural gas prices, 2008-15 ......................20 Figure 10: Consumption-weighted average rates of real fuel taxes in EU-13 and EU-15 from 19902015

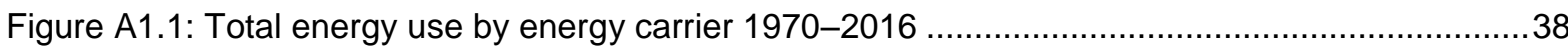
Figure A1.2: Swedish greenhouse gas emission 1990-2015 in thousand tonnes excluding foreign

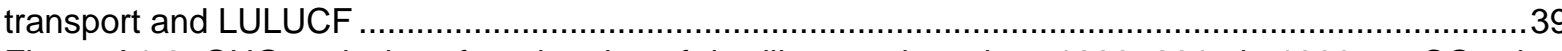
Figure A1.3: GHG-emissions from heating of dwellings and services 1990-2015 in 1000 ton $\mathrm{CO}_{2}$-ekv. 


\section{Introduction}

There is a broad consensus that a successful strategy for fighting climate change involves the decarbonization of electricity and the electrification of transport and buildings. Although electricity is indeed key, the consensus view needs to be qualified, at least for the two reasons studied in this report. The first is that fiscal policy is currently, or could become, a barrier to the electrification of transport and buildings. The second is that, even if the fiscal policy barrier were eliminated, electrification is only one option among others; each country will weigh the pros and cons of the options. This report argues that fiscal policy should be aligned with the goals of decarbonization and cleaner air, and should be neutral with respect to the options.

The background is the Paris Agreement, which committed the international community to achieving carbon neutrality between 2050 and 2100. In that context, the EU has a binding target of reducing greenhouse (GHG) emissions by 40 per cent in 2030 and a political objective of reducing them by $80-$ 95 per cent by 2050, in both cases compared to 1990 levels. To date, most decarbonization in the EU has involved improved energy efficiency and the decarbonization of electricity through the penetration of renewable power and a reduction in the use of fossil fuels in generation. While policy support for these efforts must continue, as the European Commission's Clean Energy For All Europeans (EC 2016a) acknowledges, the focus must now turn to decarbonizing transport and buildings, ${ }^{1}$ which account for about 60 per cent of EU energy-related GHG emissions. ${ }^{2}$ A major theme in that policy document is that consumers will be active participants and at the centre of the energy transition; this reinforces the importance of getting final energy prices right and minimizing pricing distortions, including those due to fiscal policy. ${ }^{3}$

Decarbonizing the energy consumed in transport and buildings will be much more difficult than decarbonizing electricity because it requires inter alia changing consumer habits, replacing the vehicle fleet and heating/cooling systems, and making significant investment in infrastructure. While addressing the challenges of climate change, public policy will also be tackling other environmental concerns, in particular local air pollution and related health and economic problems. Fiscal policy can play an important supporting role in realizing these policy objectives as efficiently as possible. It should at least not act as a barrier to their realization.

In addition to the Introduction, there are four sections to the report and two annexes. Section 2 explains the consensus on the key role of electricity for decarbonisation and offers qualified support for that view. It illustrates that, to date, electricity has been the central instrument used in the EU to decarbonize the energy sector. By way of support for that view, it also summarizes a case study included in Annex 1 that illustrates the important role played by electricity in the decarbonization of the Swedish economy, and the role of economy-wide environmental taxation.

Section 3 analyses two qualifications to the consensus view. First, it explains how fiscal policy in some EU Member States is, or threatens to become, a barrier to the electrification of transport and buildings. The review of a German case study illustrates the argument. Second, there is a summary of a case study from Annex 2 on the UK debate over the decarbonization of heat. That study illustrates that, at least in the UK, there are alternative paths to decarbonizing heat, with electrification competing with the

' On 30 November 2016 the Commission proposed an update to the Energy Performance of Buildings Directive to help promote the use of smart technology in buildings and to streamline the existing rules. There are also EC initiatives regarding decarbonization in the transport sector, including the 'Europe on the move initiative' that aims, inter alia, to make traffic safer, encourage smart road charging, and reduce $\mathrm{CO}_{2}$ emissions, air pollution, and congestion.

${ }^{2}$ Currently, buildings are responsible for about $40 \%$ of energy consumption and $36 \%$ of $\mathrm{CO}_{2}$ emissions (see 'Buildings', Energy Efficiency, European Commission, https://ec.europa.eu/energy/en/topics/energy-efficiency/buildings). Transport accounts for about a quarter of European greenhouse gas emissions (see: 'A European Strategy for low- emission mobility', Climate Action, European Commission, https://ec.europa.eu/clima/policies/transport_en).

3 'Commission proposes new rules for consumer centred clean energy transition', European Commission, 30 November 2016, https://ec.europa.eu/energy/en/news/commission-proposes-new-rules-consumer-centred-clean-energy-transition. 

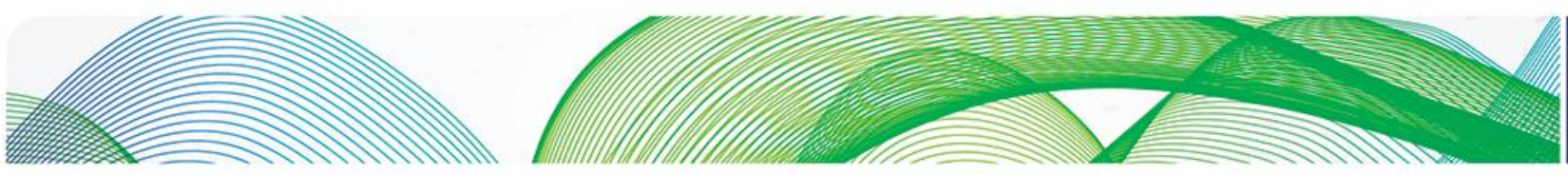

greening of natural gas. It raises questions about the limits of fiscal policy and markets when governments intervene directly in order to realize their policy goals.

Based upon the previous sections and public economics, Section 4 proposes a framework of guidelines for aligning energy sector fiscal policy with the objectives of decarbonization and improved air quality in individual EU Member States. It emphasizes that fiscal policy for the energy sector should distort the economy as little as possible, correct distortions by internalizing environmental externalities (such as $\mathrm{CO}_{2}$ emissions), be neutral with respect to the options for achieving environmental objectives, and be part of a comprehensive fiscal reform that is sensitive to the distributional consequences of reform as well as its efficiency properties.

The final section draws conclusions and recommends that the guidelines be used to review and reform fiscal policy in individual Member States, especially those where such policies appear to be acting as a barrier to decarbonization. The emphasis is on creating a level fiscal playing field that provides the signals needed to promote low-carbon investment and innovation.

Three caveats are in order on the scope of the report.

- First, the emphasis here is on fiscal policy to reduce $\mathrm{CO} 2$ emissions, with reduced air pollution and improved health referred to as co-benefits of decarbonization. As just mentioned, the guidelines for fiscal policy in Section 4 touch on the taxation of $\mathrm{CO} 2$ and other environmental externalities. However, fully addressing these other pollutants goes beyond the scope of this report.

- Second, this report does not begin to consider all the relevant technologies - electric and others that could play a role in the clean energy transition. Rather, it focuses on what appears to be an important tension between fiscal policy and the consensus view that supports electrification of transport and buildings.

- Third, this report stays mainly at an EU level, drawing on a few national case studies to illustrate the challenges and possible answers. Detailed country studies are needed to draw conclusions about fiscal policy reform in each.

The intention is to address these other issues in future research. 


\section{Electricity and the consensus view}

\subsection{The consensus view}

The consensus among most policy makers and experts is that decarbonization of energy depends heavily on electricity. As an illustration of this consensus, the Energy Transitions Commission (ETC) recently set out this approach as the critical step in a global strategy for decarbonization:

Energy transition 1 - decarbonization of power combined with extended electrification could account for the largest share of emissions reductions between now and 2040. (ETC 2017, page 15).

The ETC strategy identifies other elements. They include: decarbonizing activities that cannot be electrified cost effectively, for instance agriculture, some industries and certain transport modes; improved energy productivity; and carbon sequestration. Nevertheless, the ETC approach reflects the consensus that electricity is the most important element in the strategy for decarbonizing energy. The strategy first involves a switch from fossil fuels to renewables in the generation of electricity. ETC (2017) argues that by 2040 intermittent renewables could reach 45 per cent of the global power mix, with other zero-carbon power sources representing about 35 per cent and unabated fossil fuels the remaining 20 per cent. The second element of the transition involves extending electricity to a wider range of economic activities. The ETC scenario suggests that 10-20 per cent of all fossil fuels use could be eliminated on a global scale by 2040 and that the initial opportunities are greatest in light vehicle transport and building heat services.

For the EU to meet its own political target for 2050, the European Commission's Energy Roadmap 2050 (EU 2011) suggests an almost complete elimination of emissions from electricity, together with a partial electrification of transport and heating. ${ }^{4}$

The case for the consensus view can be made by reference to five arguments: political attractiveness, technical feasibility, economic feasibility, the 'no-regrets' strategy, and environmental co-benefits.

\subsubsection{Political attractiveness}

First, the concentration of a significant share of $\mathrm{CO}_{2}$ emissions in a relatively small number of power stations makes it relatively easy for governments to target and reduce emissions in the electricity sector. This also helps to explain why the costs of managing a carbon tax, or the EU Emissions Trading System (ETS), are significantly lower than managing other important tax sources, such as income tax and VAT. Consumers are also unaware of the impact of the EU ETS on prices. These features will facilitate further decarbonization of electricity.

Second, the falling cost of both renewable energy and batteries weakens political opposition to decarbonization. This is partly due to the falling costs of the technology, but also to the use of competitive mechanisms (such as auctions). Other technologies will be required to provide short-term and longer-term backup for intermittent renewables. However, the trend is clearly away from coal in the power sector in the EU, especially in western Europe, with a number of countries phasing out coal. ${ }^{5}$ Natural gas will continue to play a role in some countries, mainly as a backup to intermittent renewables until less expensive alternatives exist.

Third, governments at most levels now consider renewable energy and the electrification of transport as an attractive option because of the co-benefits for job creation, the development of new businesses

\footnotetext{
4 '2050 low carbon economy', Climate Action, European Commission, https://ec.europa.eu/clima/policies/strategies/2050_en. ${ }^{5}$ There are many reasons why coal is being phased out in some countries; these include increasingly stringent EU emission performance standards, a perception that carbon capture and storage technologies are not economic (especially with low prices for $\mathrm{CO}_{2}$ emissions), and the absence of financial market support for investment that could be stranded soon after a plant has been built.
} 
with global markets, and the potential to improve air quality and health (a topic picked up again later in this section).

Fourth, there is a geopolitical reason for EU countries to support the decarbonization of electricity and the electrification of transport and heating. Reliance on locally generated renewable power reduces dependence on imported fossil fuels. It also implies a lowering of pressure on the balance of payments of most EU Member States. ${ }^{6}$ By contrast, in the USA, the abundance of fossil fuels - notably low-cost shale gas - makes renewable power less important in terms of geopolitics.

Although there is growing political consensus for the use of clean electricity (especially renewable power) as the main energy vector for decarbonization, political support is not unconditional. Some consumers are willing to pay a premium for renewable energy, but most are concerned about the level of prices. In many countries, consumers pay much higher bills to subsidize decarbonization. In some, consumers actively participate in the decarbonization process and can benefit directly from it - for instance through self-generation that may lower their bills. In other countries, especially where renewable electricity is large in scale and at grid-level, consumers pay higher bills but are not actively involved. Looking forward, the electrification of heating for existing buildings may involve a change in the consumer experience, in addition to significant investments both by the consumer and the local distribution company. These changes and higher prices will encounter consumer resistance. The electrification of heat and transport will also meet resistance from the suppliers of fossil fuels.

In short, there has been political support for decarbonization of energy via the electricity sector but there are barriers ahead, especially where consumers see no direct benefit and where the opposition from vested interests is strong. Fiscal and other policies should encourage efficient decisions in order to minimize the cost of meeting environmental objectives.

\subsubsection{Technical feasibility}

Decarbonization of electricity is technically feasible due to the availability of alternative proven lowcarbon generation technologies, demand-side energy resources, and the fact that different energy resources can all be despatched in an integrated electricity system. These alternative technologies are increasingly capable of behaving like conventional generation facilities in that they are able to forecast their own production and participate in grid services. For the time being, conventional flexible capacity is still needed to operate the system. However, in the future, storage, interconnections, distributed generation, and demand response will reduce the need for conventional generation.

Another factor that makes decarbonization of electricity feasible is that the same companies are able to generate electricity from different sources and can progressively decarbonize their own generation mix.

Commercially available technologies also exist to support the electrification of transport (electric vehicles, for example) and of buildings (heat pumps or district heating, among other technologies). There are proven non-electric alternatives for transportation and heating, for instance using natural gas and renewable gas. The advantage of natural gas over oil is related to the reduction in local pollutants, notably $\mathrm{NO}_{x}$ and particulates. However, unless the $\mathrm{CO}_{2}$ emissions of gas are being captured and used or stored, there will be limits to the role that natural gas can play in transport or buildings if the EU is to meet its 2050 targets. Hydrogen-based networks could also aid the foundation of decarbonized heat and transport sectors, but support for hydrogen would require a major political and investment decision,

\footnotetext{
${ }^{6}$ The reduced vulnerability to imported fossil fuels is one of three main reasons identified in EC (2007) for pursuing decarbonization. 'Meeting the EU's commitment to act now on greenhouse gases should be at the centre of the new European Energy Policy for three reasons: (i) $\mathrm{CO}_{2}$ emissions from energy make up $80 \%$ of EU GHG emissions; reducing emissions means using less energy and using more clean, locally produced energy, (ii) limiting the EU's growing exposure to increased volatility and prices for oil and gas, and (iii) potentially bringing about a more competitive EU energy market, stimulating innovation technology and jobs.' (Communication from the Commission to the European Council and the European Parliament - An energy policy for Europe', 10 January 2007, http://eur-lex.europa.eu/legal-content/EN/TXT/?uri=celex:52007DC0001)
} 
and a clear improvement of its economics. Nevertheless, electricity will compete with other low-carbon technologies.

\subsubsection{Economic feasibility}

The economics increasingly favour further decarbonization of electricity and could also favour the electrification of transportation and heating. Financial markets and energy companies are certainly pointing in the direction of decarbonization. ${ }^{7}$

With the rapid decline in the costs of renewable power and storage technologies, the political commitment to renewable power is easier to maintain and there is a growing conviction that the future of electricity will be renewable. Investors in power stations running on fossil fuels face the risk of stranded assets, and this is increasingly being factored into investment decisions. The latest recommendations from the Financial Stability Board on the disclosure of climate-related financial risks are a reflection of investors' (and Central Bankers') growing concern about assets being stranded as a result of competitive, consumer, or policy limits on the use of fossil fuels. ${ }^{8}$

In energy markets, networks are key to the economics of decarbonization. Existing electricity networks allow decarbonization of electricity through the replacement of fossil-fired generation by renewables, and enable the backing up of intermittent wind and solar generation. These same electricity networks can be used (and developed) to electrify heating and transport. Furthermore, the existing electricity networks permit a modular approach to electrification. However, investments in networks are needed to accommodate renewables, especially at low voltage levels.

Furthermore, there are non-electric zero-carbon energy sources - such as renewable gas or hydrogen - that may be more economic in some areas. In particular, one should not underestimate the potential cost of electrifying heat in areas with a high penetration of natural gas for heating and with little if any district heating. In the UK, for instance, extensive electrification of heat would be extremely expensive and may be economically less attractive than the greening of natural gas and the continued utilization of the natural gas network. ${ }^{9}$ Again, networks are probably the key economic determinant of what will be the most efficient way to decarbonize end markets; in some cases electricity will compete with other networks.

\subsection{4 'No-regrets' strategy}

There is debate about whether GHG emissions will fall if electrification occurs before electricity is more fully decarbonized. The case for early electrification is based on there being 'no regrets': that emissions would fall now, with the current mix of generation. Furthermore, waiting longer risks the locking in of carbon-intensive activities.

The no-regrets case is easiest to make with regard to electric vehicles. The European Electricity Industry Association, Eurelectric, makes the case.

In the transport sector, switching to electricity is already a no-regret option for reducing GHG emissions today. When calculating the indirect GHG emissions related to the production of electricity, using today's average European electricity mix, an EV requiring $10 \mathrm{kWh}$ per $100 \mathrm{~km}$ is responsible for less than $50 \mathrm{~g}$ $\mathrm{CO}_{2} / \mathrm{km}$. This represents a fraction of the carbon emissions produced by even the most efficient conventional cars available on the market today, and significantly lower than the average target under current regulation for all new cars of $95 \mathrm{~g} \mathrm{CO}_{2} / \mathrm{km}$ by 2021. In addition, the efficiencies delivered by an electric vehicle are three times that of an internal combustion engine (ICE) due to lower heat losses during the energy conversion process. ${ }^{10}$

\footnotetext{
7 'Clean Energy Is Trouncing Oil, Gas and Coal in Trump Era', Bloomberg, 18 July 2017,

https://www.bloomberg.com/news/articles/2017-07-18/clean-energy-is-trouncing-oil-gas-and-coal-in-trump-era

${ }^{8}$ Website of the Task Force on Climate-related Financial Disclosures: https://www.fsb-tcfd.org.

${ }^{9}$ This is addressed in Annex 2 (on the UK heating market, by Malcolm Keay) and in Section 3 of the main report.

10 'Electrification: a winning strategy for Europe', The Energy Industry Times, June 2017, Page 13,

www.eurelectric.org/media/329557/20170604-the-energy-industry-times-electrification-a-wining-startegy-for-europe.pdf.
} 
The Eurelectric conclusion is consistent with an article in the Journal of Industrial Ecology (Hawkins et al., 2012) which found that electric vehicles powered by the European electricity mix at that time would decrease the global warming potential by 27-29 per cent relative to gasoline vehicles and by 17-20 per cent relative to diesel vehicles, assuming a $200,000 \mathrm{~km}$ lifetime. Even if electric cars required a very high $20 \mathrm{kWh}$ per $100 \mathrm{~km}$ (instead of the assumed $10 \mathrm{kWh}$ in the Eurelectric example), emissions with the current generation mix in Europe would be very similar to the target of $95 \mathrm{~g} \mathrm{CO}_{2} / \mathrm{km}$, which supports the no-regrets conclusion. Furthermore, financial markets, automobile companies, and organizations like OPEC and the IEA all clearly anticipate the accelerating penetration of electric vehicles.

However, in order to draw definitive conclusions about the no-regret strategy, a comparison of life-cycle emissions of different technologies, as well as future costs - under different assumptions about the scale of manufacturing, the electricity mix, and many other characteristics - is required. ${ }^{11}$ It is also necessary to make judgements about future regulatory support for electrification and assumptions about future cost trends, notably in relation to battery costs. Suffice it to say here that there are many options to consider apart from electric vehicles, such as: fuel cells, the increased use of natural gas and biofuels, the replacement of old vehicles, and new technologies that combine improvements in energy efficiency of ICE with a higher quality of fuels. There are also alternatives to the electrification of buildings.

Whether one concludes that electrification is a 'no-regrets', or a 'low-regrets' strategy, it is clear that fiscal policy should not actively discourage electrification. It is also worth re-emphasizing the risk of locking in the carbon intensity associated with conventional ICE vehicles, natural gas vehicles, and heating systems that rely on fossil fuels.

\subsubsection{Environmental co-benefits and costs}

Electrification also produces co-benefits with respect to pollution related to the combustion of oil products. The EU's urban population is currently exposed to unacceptably high levels of air pollution from road traffic, including fine particulate matter (PM2.5), nitrogen oxides, and ozone, causing serious health problems and related costs. ${ }^{12}$ The example of diesel illustrates the importance of dealing with all of the relevant contaminants, not just $\mathrm{CO}_{2}$. Although diesel engines are more efficient than petrol engines (and emit less $\mathrm{CO}_{2}$ ), they emit higher levels of air pollutants, in particular nitrogen dioxide and fine particulates. A switch to electric vehicles is one way to reduce these emissions.

However, Hawkins et al. (2012) also points to the significant increases in human toxicity, freshwater eco-toxicity, freshwater eutrophication, and metal depletion that are largely due to the electric vehicle supply chain. A reduction in the environmental impact of electric vehicles therefore requires not only further decarbonization of electricity, but also reductions in the impact of the vehicle production supply chain. Fiscal policy should be aligned both with decarbonization and these wider environmental objectives.

There are many policies for improving local air quality. These include fiscal policy, good low-carbon public transport, limiting access (through prices or otherwise) for vehicles to the city centre, the provision of bicycle lanes, and urban design facilitating low-carbon mobility. These policies should be in alignment.

\subsection{The evidence to date Th $^{13}$}

Electricity has played a central role in the EU's decarbonization strategy to date. Since 1990, GHG emissions in the EU have decreased by over 1,300 million tonnes of $\mathrm{CO}_{2}$ eq. (Figure 1). The EU emitted

\footnotetext{
11 See, for instance, the following study that refers to US conditions: 'U.S. DRIVE Releases Cradle-to-Grave Analysis of LightDuty Vehicles', Office of Energy Efficiency \& Renewable Energy, 9 June 2016, https://energy.gov/eere/fuelcells/articles/usdrive-releases-cradle-grave-analysis-light-duty-vehicles.

12 See Eurelectric (2017) for a summary of the studies that address local pollution and health impacts of pollution.

${ }^{13}$ Most of the data in this sub-section is from EEA (2016a).
} 

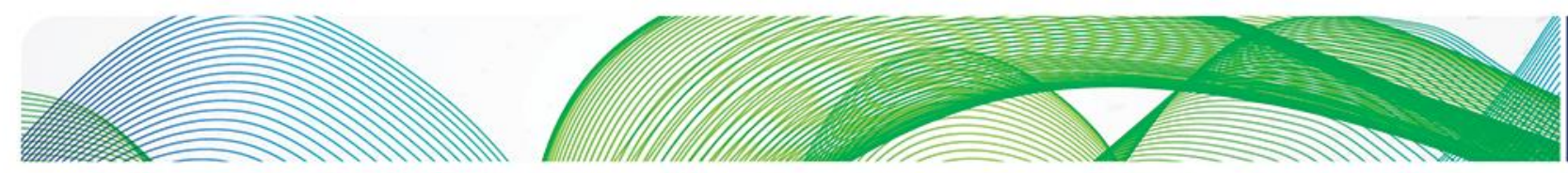

4,282 million tonnes of $\mathrm{CO}_{2}$ eq. in 2014, 24 per cent less than in 1990. The reasons for declining emissions include the decoupling of economic growth and emissions; the economic recession of 200814; lower carbon intensity of energy, notably due to the increased penetration of renewables and the switch from coal to gas; and lower conventional primary energy intensity. In absolute terms, the largest emission reductions occurred in the energy combustion sector, in particular from industry and electricity. The absolute reductions from electricity are especially evident in the period after 2008 , which coincides both with an economic recession and with the accelerated penetration of renewable power.

Figure 1: Total EU-28 CHG Emissions excluding LULUCF ${ }^{14}$, 1990-2014 (ktC02 eq.)

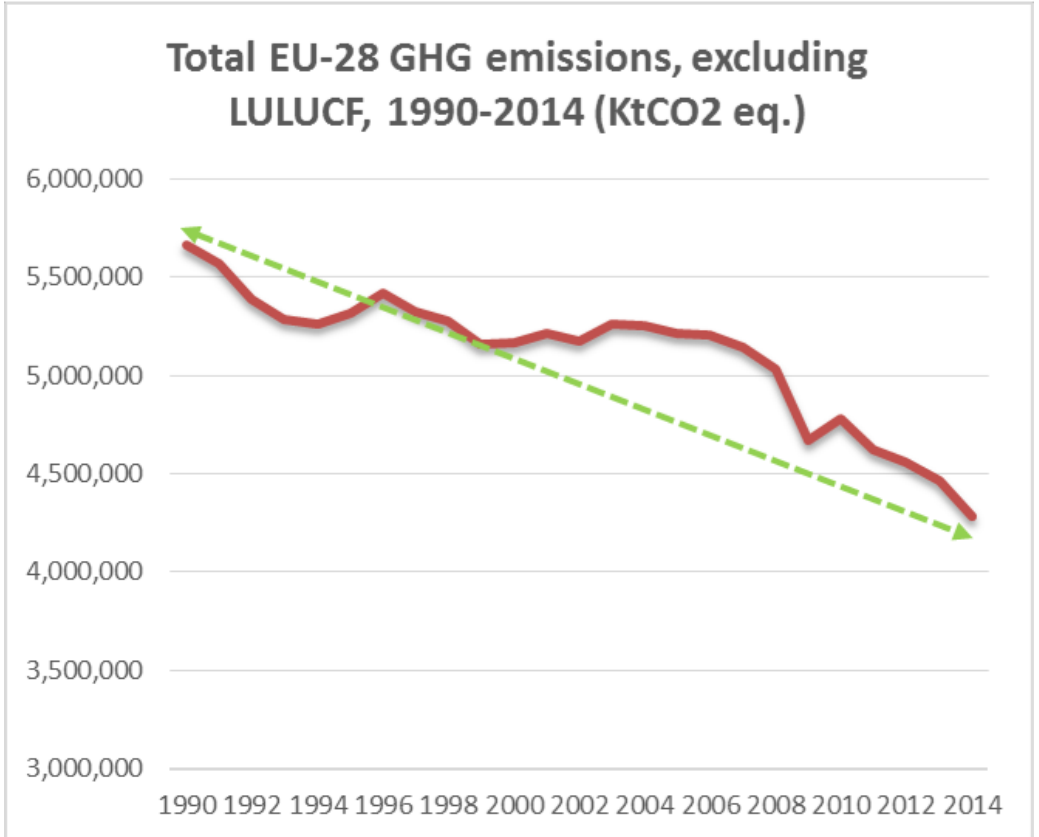

Source: EEA (2016a), page 10.

Note: the solid red curve is the level of emissions and the green dotted line is the trend over the period.

Figure 2 reflects the importance of electricity to the overall reduction in GHG emissions between 1990 and 2014, especially after 2008. Energy supply (electricity and centralized heat) is the largest emitter of GHG and, with annual reductions of 346 million tonnes equivalent, is second only to industry in absolute GHG emission reductions since 1990. These reductions reflect improved transformation efficiency (lower heat production and higher electricity production), lower carbon intensity of fuels (related to the shift from coal to gas), and a substantial increase in the share of renewables. The category of energy supply obscures somewhat the emissions from electricity since the latter are combined with emissions from centralised heat. Eurelectric estimates that the carbon intensity of electricity generation fell by 35 per cent between 1990 and 2014 and that in 2015, 56 per cent of electricity generation was carbon free (27 per cent nuclear and 29 per cent renewable). ${ }^{15}$ There is still significant potential to reduce GHG emissions in electricity, notably through the phasing out of coalfired generation and the further penetration of renewables. Another important point to note in Figure 2 is that, contrary to other big sectors, transport has been increasing its emissions in the last few years. After the economic crisis, people are starting to travel more and to buy bigger cars.

\footnotetext{
${ }^{14}$ LULUCF refers to Land Use, Land-Use Change and Forestry.

15 'Electrification of society - A Bright Future for Europe', Kristian Ruby Secretary General, Eurelectric, www.eurelectric.org/media/323030/ruby.pdf.
} 
Figure 2: GHG Emissions by sources EU-28, 1990-2014

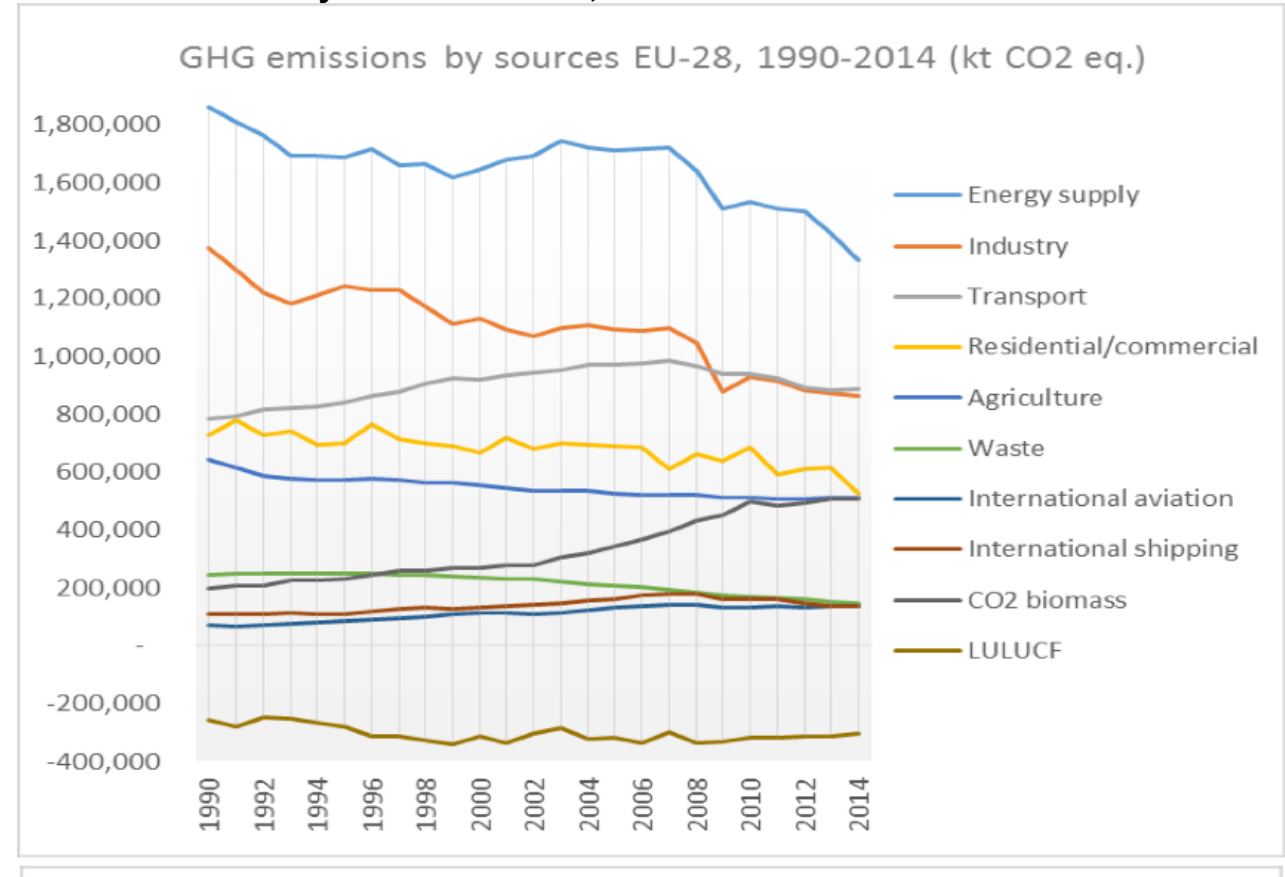

GHG emissions by sources EU-28, 1990-2014 (\%)

Total excl. LULUCF

$-24 \%$

$\mathrm{CO} 2$ biomass

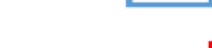

International shipping

International aviation $24 \%$

$\begin{array}{rr}\text { Waste } & -40 \% \\ \text { Agriculture } & -20 \% \square\end{array}$

Residential/commercial

$-28 \%$

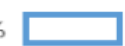

Transport

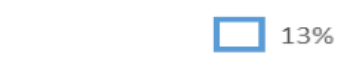

Industry

$-37 \%$

Energy supply

$-28 \%$

$-75 \%$

$-25 \%$

$25 \%$

$75 \%$

$125 \%$

$175 \%$

Source: EEA (2016a) page 17.

Figure 3 reveals why $\mathrm{CO}_{2}$ emissions have fallen in the power sector: declining demand, falling output from coal and gas and, in particular, rising output from renewable power. It is important to stress that the EU target for renewable energy - that renewables account for 20 per cent of final energy demand by 2020 - refers to demand for all sources of energy, not just electricity. Yet electricity has been, and still is, the main vehicle for achieving the target. 
Figure 3: EU Power generation 2010-16 (TWh)

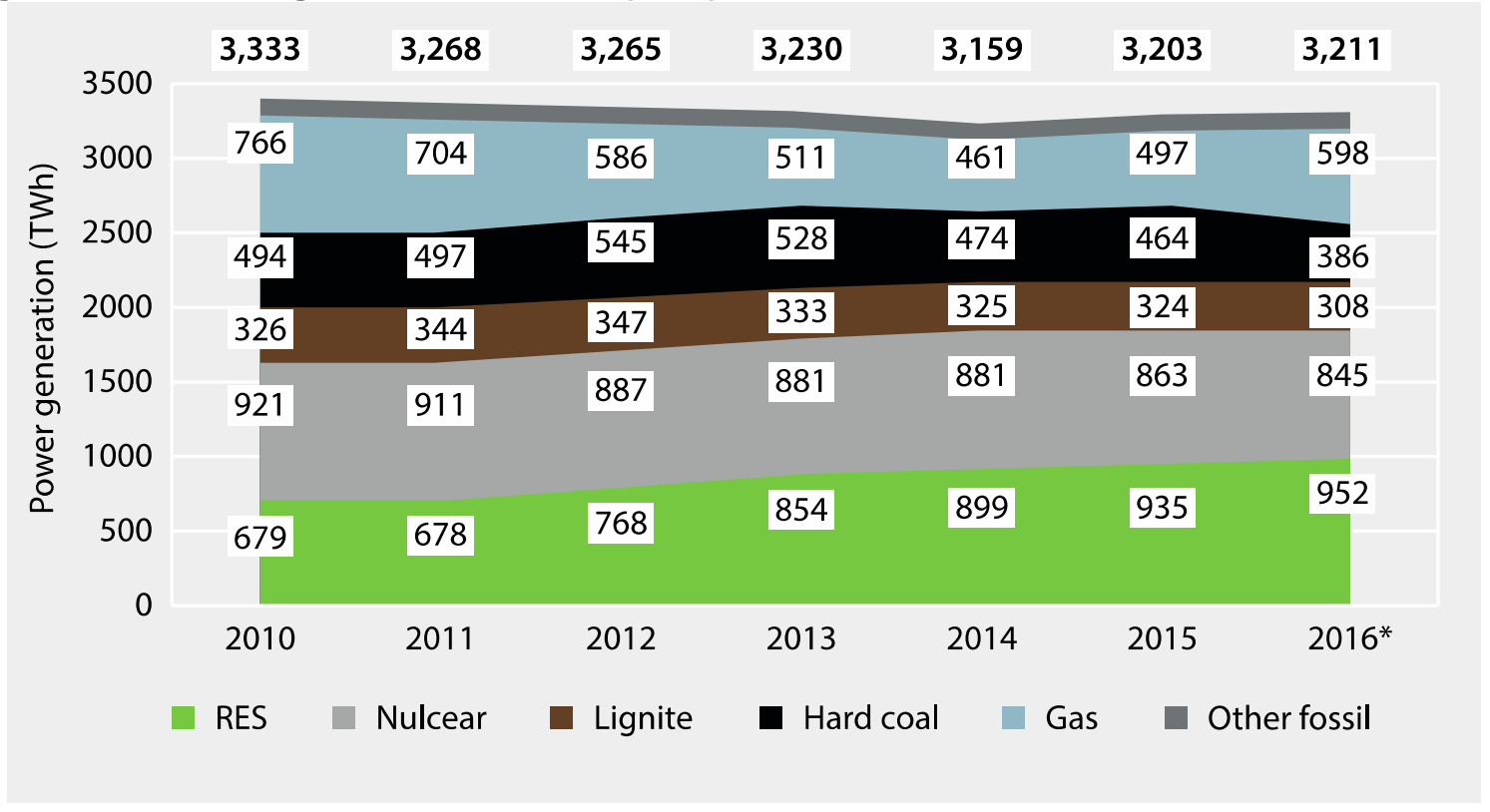

Source: Sandbag (2017) page 7.

Apart from electricity, annual emissions related to energy used in the residential sector (in heating and cooling, for example) also decreased over the period 1990-2015, mainly due to efficiency improvements associated with better insulation and building standards, and lower carbon intensity of fuels. It is not possible from these data to determine the trend for GHG emissions from residential, commercial, and industrial buildings. However, GHG emissions from buildings still amount to about 35 per cent of EU GHG emissions.

On the negative side, $\mathrm{CO}_{2}$ emissions from road transportation increased by 124 million tonnes between 1990 and 2014. They rose steadily from 1990 to 2007, then fell during the recession but have been rising again since 2013. Despite increases in efficiency and declining carbon intensity of fuels, road transport in the EU still represents about a third of $\mathrm{CO}_{2}$ emissions in sectors not covered by the EU ETS, and transport overall accounts for about 25 per cent of GHG emissions.

In sum, over the period 1990-2015, electricity has played a major role in European decarbonization, whereas transport based on petroleum products has contributed to a higher absolute level of GHG emissions. Looking forward, it will be necessary to continue decarbonizing electricity, but the greater task ahead is to decarbonize transport and buildings.

\subsection{Sweden $^{16}$}

The Swedish case involves almost complete decarbonization of electricity, significant decarbonization of heating, good potential for decarbonization of transport, and a successfully growing economy. According to the latest statistics (2014) from the International Energy Agency (IEA, 2017), the average Swede releases 3.86 tonnes of carbon dioxide $\left(\mathrm{CO}_{2}\right)$ per year into the atmosphere, compared with the OECD Europe average of 6.05 tonnes and the US average of 16.22 tonnes. ${ }^{17}$

It is worth understanding the reasons for this success story and identifying the relevant policy mechanisms that have supported decarbonization of energy in Sweden.

\footnotetext{
${ }^{16}$ See Annex 1 for the case study on Sweden by Klaus Hammes.

${ }^{17}$ These data refer to emissions from fossil combustion.
} 


\subsubsection{Overview of decarbonization and political motivation}

First, Sweden's electricity sector has been decarbonized for many decades. This is largely due to the availability of hydro resources. It also reflects a geopolitical decision to develop nuclear power in order to reduce reliance on imported oil, following the oil crises of the 1970s. As a result, hydro and nuclear each account for close to half of Sweden's electricity generation. Although Sweden announced its intention to rely 100 per cent on renewable electricity in 2040 , the country has not made a decision to shut its nuclear plants and has left open the option of building new ones without government subsidies. In any case, the country has decided that electricity will be fully decarbonized by then and that there will be sufficient decarbonized electricity to virtually eliminate the use of fossil fuels in transport and buildings. Although the original political motivation for decarbonization was geopolitical, environmental policy concerns have been an important policy motivation for many years.

Second, the heating market was, to a large extent, decarbonized before 1990, largely as a result of the use of low-carbon electricity from hydro and nuclear, and also because of some decarbonization of district heating. Combined Heat and Power (CHP) became the dominant source of district heating, which is now the market leader in the Swedish heating market. Since the 1990s, the government has continued to promote district heating and CHP, which now relies very heavily on biofuels. Again, geopolitics was the initial motivation for decarbonizing heat, but environmental concerns have motivated significant further decarbonization.

Third, for the reasons already mentioned, fossil fuels now play a marginal role in the economy, mainly for transport. The government has also adopted a plan for the decarbonization of transportation.

Figure 4 illustrates Swedish energy use by carrier, reflecting the increase in electricity, biofuels, and district heating and the decline of petroleum products.

Figure 4: Total energy use in Sweden by energy carrier (1970-2016)

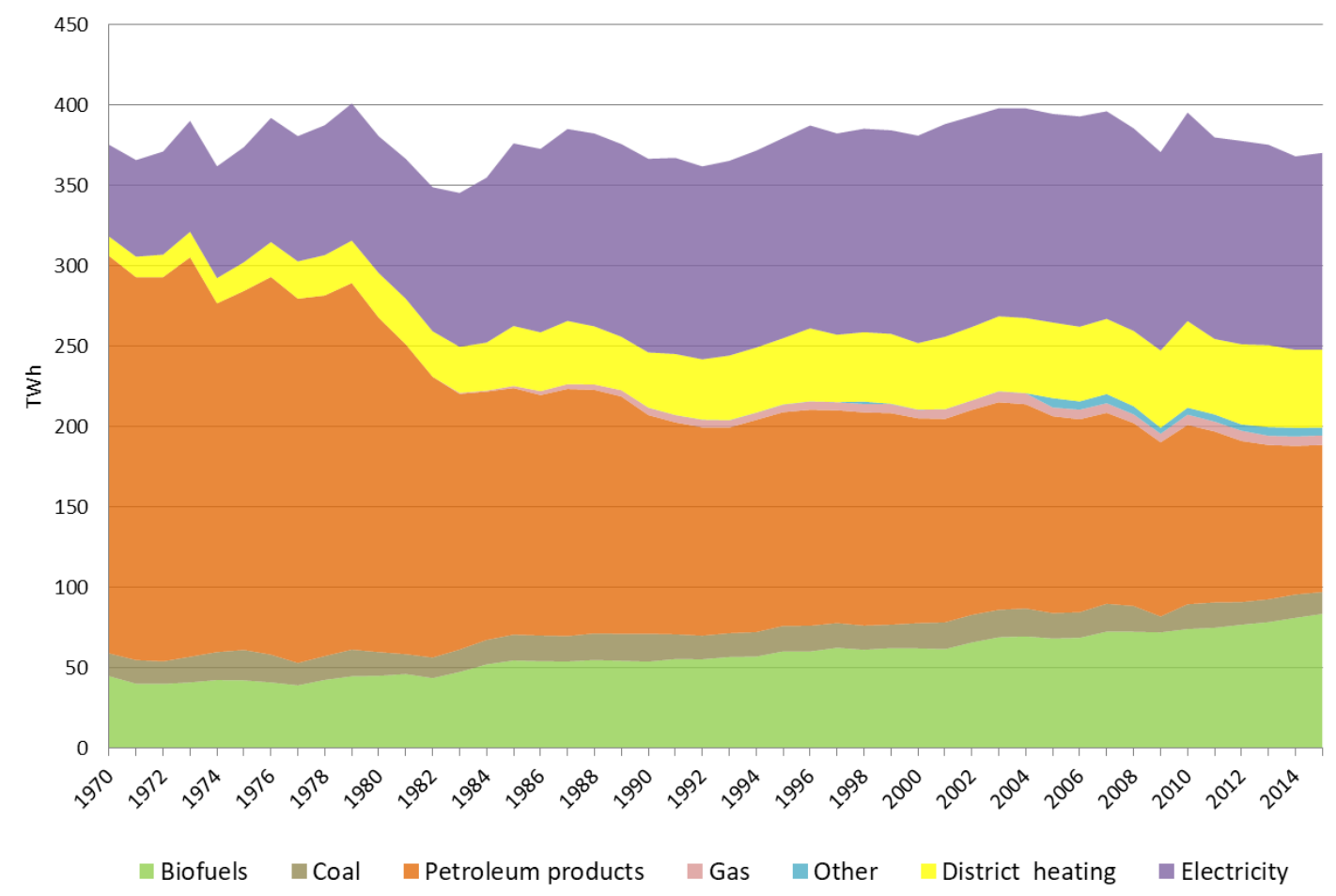

Source: Energimyndigheten, Energiläget i siffror 2017, 2017. 

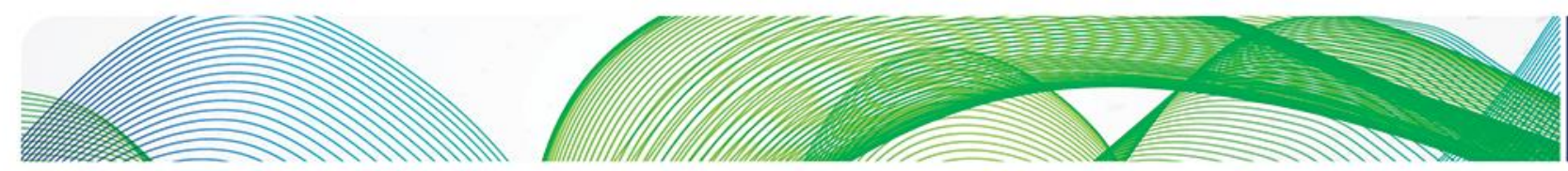

\subsubsection{Fiscal policy to support decarbonization of heat and transport}

The Swedish energy system was largely electrified and decarbonised by 1990 , but fossil fuels continued to be important in the heating and transport sectors. Since then, total emissions from heat and power generation have fluctuated, but have fallen in spite of growing heat and power demand.

Fiscal policy in Sweden has played an important role in the decarbonization of both heat and transport. Indeed, environmental taxation has been at the centre of Swedish fiscal policy since the early 1980s, with the government using the revenue as a means of reducing taxes on labour. Fiscal and other policies related to the environment are usually based on the principle of being 'technology neutral', keeping options open and allowing markets to adjust.

In 1991, Sweden introduced an economy-wide carbon tax based on the carbon content of fuels, with a limited number of industries exempted from the tax. At that time, the carbon tax accounted for about 2.4 per cent of total tax revenue. It rose in steps and is now $1.13 \mathrm{Skr} / \mathrm{kg} \mathrm{CO}_{2} .^{18}$ Sweden also introduced a sulphur tax, primarily as a measure to mitigate acid rain. These taxes put an economy-wide price on externalities and left it to the market to find the optimal way to adapt to these taxes. Environmental tax reform came back onto the agenda in the late 1990s and the budgets for 2001 and 2002 contain tax increases for fossil fuels, with revenues again being used to reduce labour taxation.

In 2016 environmental taxation amounted to Skr98 billion ( $€ 10.2$ billion) while direct subsidies amounted to only Skr7.4 billion ( $€ 770$ million). These numbers reflect the 'technology neutral' approach to taxation, internalizing negative external effects rather than picking 'winners' through technology-specific subsidy schemes. Furthermore, these numbers do not include the income transfer from consumers to producers of renewable energy through the green certificates scheme.

Fiscal policy has been especially important in the decarbonization of heat. As shown in Figure 5, the decline since 1990 in GHG emissions from the heating sector has been remarkable.

Figure 5: GHG emissions in Sweden from heating of dwellings and services 1990-2015 with vertical axis in 1000 ton $\mathrm{CO}_{2}$ eq.

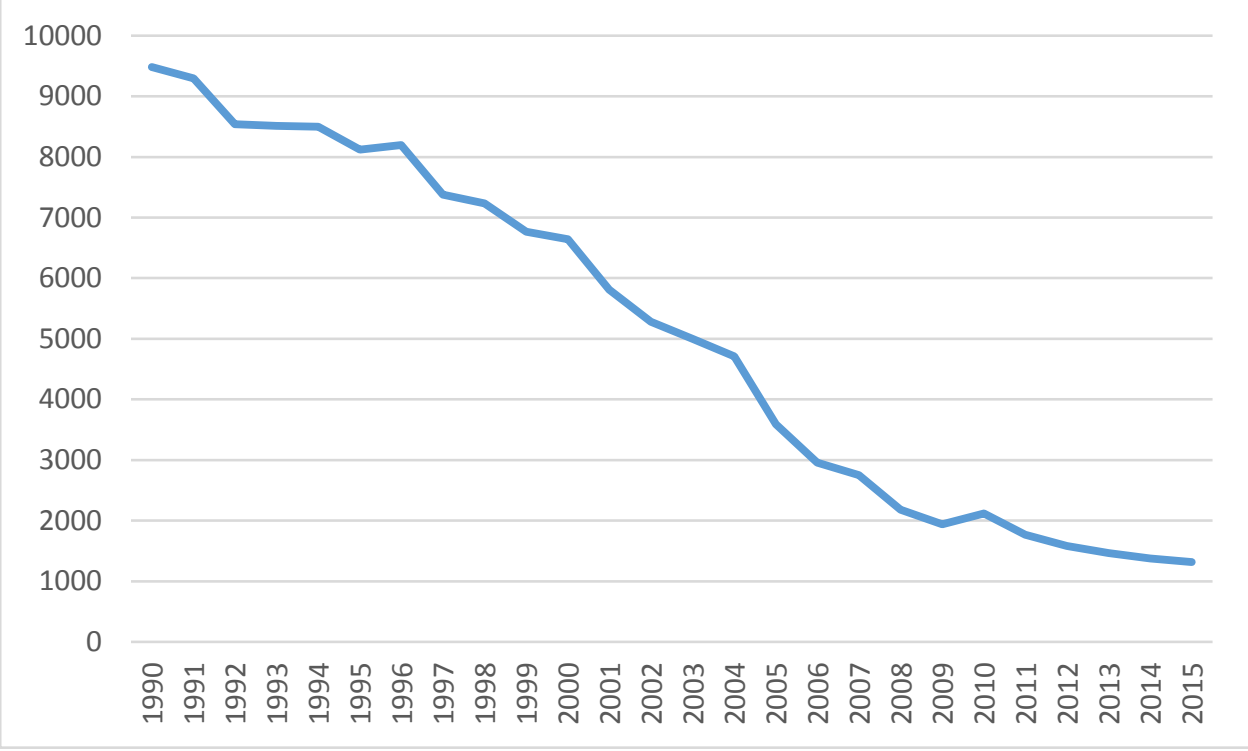

Source: EPA (2017).

Heating in Sweden can be divided into three categories.

- Space heating, water heating, and heat pumps, using electricity.

\footnotetext{
$181 \mathrm{SKr}=0.1041 €$ as of 7 July 2017 .
} 
- CHP plants using biofuels and other fuels to generate heat for district heating systems and for industrial use.

- Biomass (pellets) used by industry and in homes.

Of these three sources, CHP-based district heating is the most important.

Fiscal policy has been especially important for the development of district heating associated with CHP. Sterner et al. (2013) summarized the Swedish experience:

the $\mathrm{CO}_{2}$ tax seems to have had a major impact on fuels used for heating purposes, where biofuels and other non-fossil energy sources (such as energy from waste and surplus heat from industrial processes) have significantly increased their shares.

Biofuels and other non-fossil energies are exempt from carbon taxes and are used widely in these CHP plants. Furthermore, electricity from CHP plants burning biofuels earns green certificates, as do other sources of renewable electricity. The combination of avoided carbon taxes and green certificates makes CHP especially attractive.

Heating-related GHG emissions will continue to fall, mainly due to falling demand related to new European directives on energy efficiency and energy performance. In addition, Swedish energy policy stipulates an improvement of 50 per cent in energy efficiency by 2030. While district heating has had a successful past, the future looks dimmer for that technology both due to increasing competition from heat pumps and declining demand.

Sweden aims to decarbonize the transport sector by 2030. Apart from existing taxation, the government has used direct support schemes for cars with better environmental performance and has exempted biofuels from taxation. In 2015 the Swedish government started a new support scheme 'klimatklivet' (climate stride/leap) that includes the subsidization of a charging infrastructure for cars in municipalities and for multi-person dwellings. Furthermore, the government is supposed to introduce a bonus-malus system by 1 January 2018 - rewarding consumers who buy cars with low emissions and punishing those buying cars with high emissions. Under the new scheme, the tax exemption for biofuels will be replaced by a system based on emission thresholds $\left(\mathrm{gCO}_{2} / \mathrm{km}\right)$. This approach will favour vehicles with the lowest emissions. The most likely beneficiaries are electric vehicles, for which charging networks are being built. Hydrogen vehicles would also benefit from the system, but currently the network to support hydrogen is less developed.

\subsubsection{Price differentials}

Prices for electricity and gas in Sweden are significantly different from those in countries that rely more heavily on natural gas. For instance in 2015 , Sweden's average household gas price was $€ 0.117 / \mathrm{kWh}$ compared to a German price of $€ 0.068 / \mathrm{kWh}$ and a UK price of $€ 0.067 / \mathrm{kWh}$. Conversely, electricity prices in Sweden were $€ 0.187 / \mathrm{kWh}$, significantly lower than in Germany $(€ 0.295 / \mathrm{kWh})$ and lower than the UK (€0.218). These price differentials include taxes and levies and are consistent with a strategy of electrification of transport and buildings.

\subsubsection{Conclusion on Sweden}

Prior to 1990, the availability of hydro, together with policy decisions taken to limit dependence on imported fossil fuels, were largely responsible for the extent of Sweden's electrification and decarbonization. However, since that time, environmental taxation has played an important role in the further decarbonization of the economy - especially for heat and increasingly for transport. Although direct electrification of heating and transport is important, fiscal policy has also encouraged decarbonization of heat through district heating associated with low-carbon CHP projects. To a large degree, fiscal policy is technology neutral. 


\subsection{Conclusion}

The consensus view coincides with experience to date in the EU, at least with respect to the decarbonization of electricity generation (on average). Decarbonization paths vary from one country to another, reflecting in particular the availability of low-carbon resources and political decisions that often have little to do with environmental goals. The Swedish example coincides especially well with the consensus view. The motivation for early decarbonization was geopolitical and Sweden is fortunate to have access to renewable energy sources. Nevertheless, the case study illustrates the important role that fiscal policy can play to support decarbonisation, especially the electrification of transport and buildings.

The following section identifies two important barriers to the decarbonization of transport and buildings through electrification: fiscal policy distortions and the fact that electrification may not be the least cost decarbonization option. 


\section{Barriers to electrification}

The European Commission's latest Reference Scenario based on existing policies is relatively pessimistic about the role for electricity, especially in transport. ${ }^{19}$ According to that scenario, the share of electricity in total final energy demand is forecast to rise from 20 per cent in 2005 to 22 per cent in 2020 , and to 28 per cent by 2050. Total GHG emissions for 2030 according to the Reference Scenario will be 35 per cent below 1990 levels in 2030, and 48 per cent below 1990 levels in 2050. The most important message from the EC Reference Scenario is that current policies, which were designed to meet 2020 targets, are clearly inadequate to meet 2030 targets, and even less able to meet 2050 goals with respect to $\mathrm{GHG}$ emission reductions.

The question is: what additional role could be played by electrification in bridging the gap between the Reference Scenario forecasts and the 2050 target, and what policies are needed to make this happen? Not surprisingly, Eurelectric (2017) considers electrification to have significantly greater potential than the Reference Scenario suggests. ${ }^{20}$ For instance, they estimate that achieving the 80 per cent decarbonization target across the EU by 2050 will most likely require a 95 per cent decarbonization of road transport, and that a target 25 per cent of Europe's electric vehicle fleet becoming electric by 2030 'does not represent an unachievable objective'. Eurelectric also argues for a substantial electrification of heating and cooling, in addition to almost full decarbonization of electricity. Similar conclusions have been drawn by studies carried out for individual countries. For instance, a Monitor-Deloitte (2016, page 6) report on Spain estimates that electricity in that country will be responsible for 64-66 per cent of total final energy consumption in 2050.

The aim here is not to assess the different forecasts but to stress that electrification is underway and to point out that there is significant uncertainty about its extent and speed. The remainder of this section looks at two of the barriers to electrification: fiscal policy that penalizes electricity (accompanied by a German case study), and competition from other decarbonization options (using a case study that summarizes the UK debate over the decarbonization of heat).

\subsection{Energy prices, taxes, and levies}

The EU has recently published a report (EC 2016b) that compares costs and prices for electricity, natural gas, and oil products. It reveals a trend that makes electricity less competitive against fossil fuels, especially against oil products. Fiscal policy is an important part of that trend.

\subsubsection{Electricity prices, taxes, and levies}

The EC report identifies three cost components of electricity prices: energy, networks, and taxes and levies.

- The energy component includes the wholesale cost of energy plus the retail supply cost.

- The network component includes the cost of transmission and distribution.

- Levies and taxes include VAT, environmental and excise taxes, and levies to cover the extra costs of renewables, CHP, energy efficiency, nuclear, security of supply, social, and other policy objectives.

Average final electricity prices for residential consumers in the EU increased at an average annual rate of 3.2 per cent between 2008 and 2015; this was primarily due to rising taxes and levies (EC 2016b,

\footnotetext{
${ }^{19}$ See 'EU Reference Scenario 2016 Energy, transport and GHG emissions Trends to 2050', European Commission, 20 July 2016 ,

https://ec.europa.eu/energy/sites/ener/files/documents/20160712 Summary Ref scenario MAIN RESULTS\%20\%282\%29web.pdf, page 10 .

20 'A Bright Future for Europe, The value of electricity in decarbonising the European Union', Eurelectric, www.eurelectric.org/media/318404/electrification_report_-_a_bright_future_for_europe-2017-030-0291-01-e.pdf.
} 

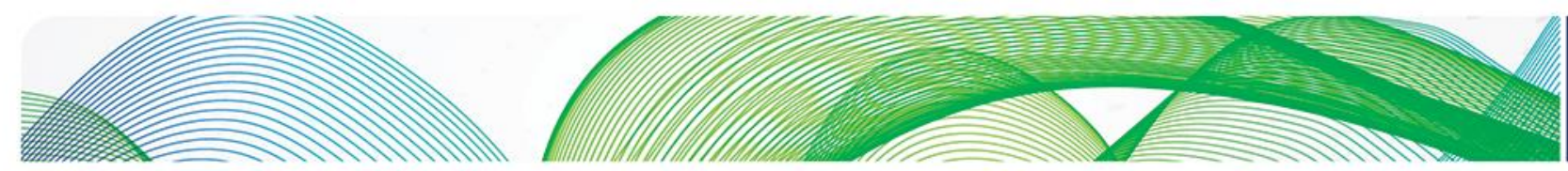

page 5). Figure 6 reflects that trend for the weighted average electricity prices in the EU-28 for residential consumers (Eurostat category DC). While energy costs fell from 46 to 36 per cent of the average price, and network costs were steady at 26 per cent, taxes and levies rose from 28 per cent to 38 per cent. (EC 2016b, pages 5-6).

Figure 6: Components of weighted average household electricity prices 2008-15

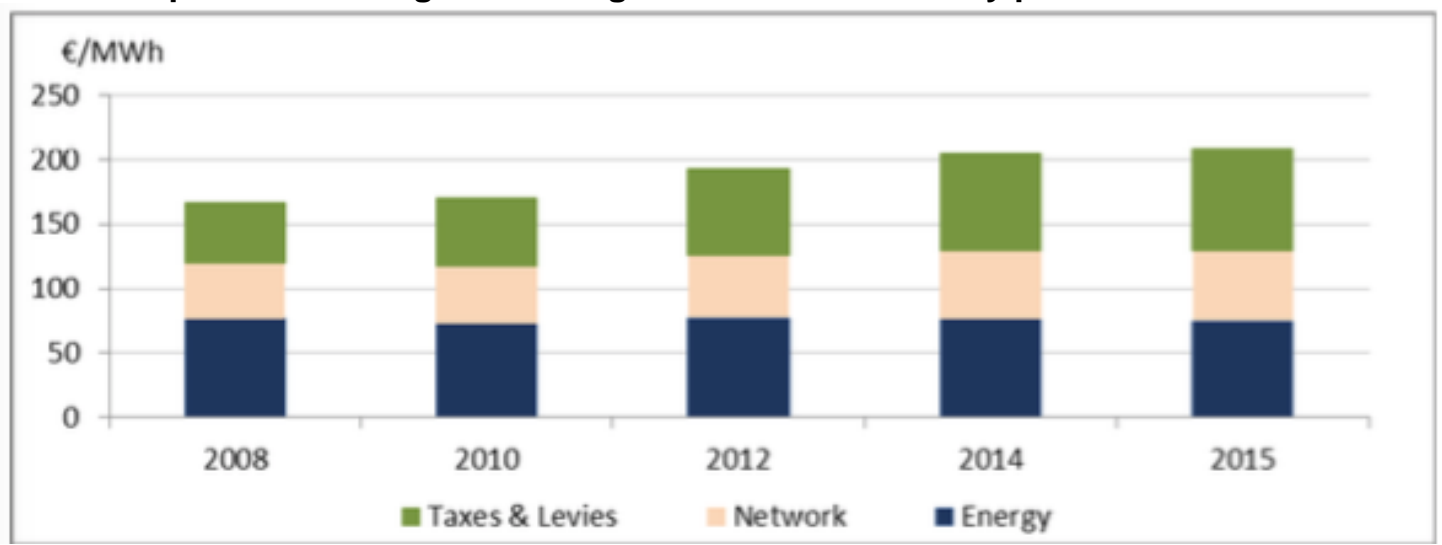

Source: EC (2016b), page 5.

Taxes and levies vary significantly among EU Member States and are now particularly high - both in absolute terms and as a share of final prices - in Germany, Denmark, Spain, and Portugal (see Figure 7). The increase in residential consumer prices of electricity especially affects the poorest families, because electricity as a share of the family budget falls as family income rises. This is not only a concern from an equity perspective, although it certainly is that. In some countries it also leads to serious and widespread consumer dissatisfaction with the electricity sector and with policies for which consumers see no direct benefits. This should be a concern for the European Union and for each Member State, since dissatisfaction puts the decarbonization strategy at risk and could fuel populist proposals that can undermine investor confidence and increase the costs of the system.

Figure 7: National electricity retail prices for households in the EU in 2015

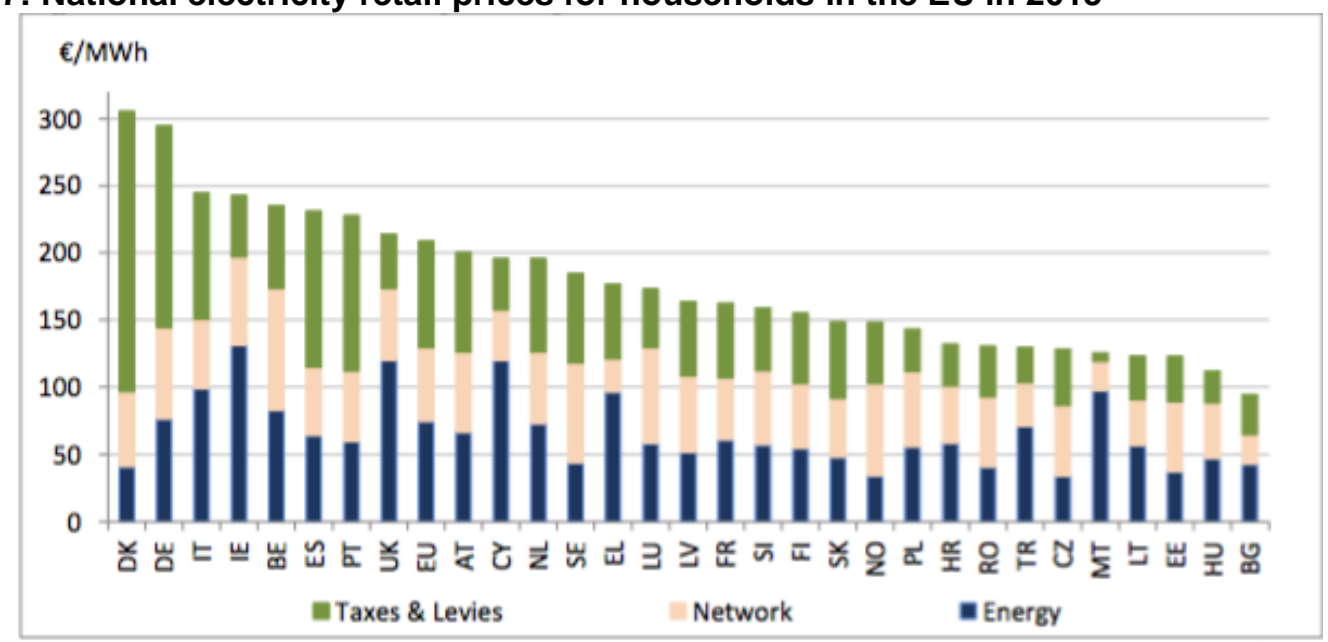

Source: EC (2016b), page 6.

As illustrated in Figure 8, the rising share of levies and taxes in average electricity prices can be explained largely by the penetration of renewable energy and the decision to finance these renewables through levies on the electricity price. On average, the sub-component of renewable energy and Combined Heat and Power (CHP) has risen from 14 per cent to 33 per cent of taxes and levies over the period. 
Figure 8: Share of the sub-components (weighted EU average) for taxes and levies in household prices (DC) in 2015

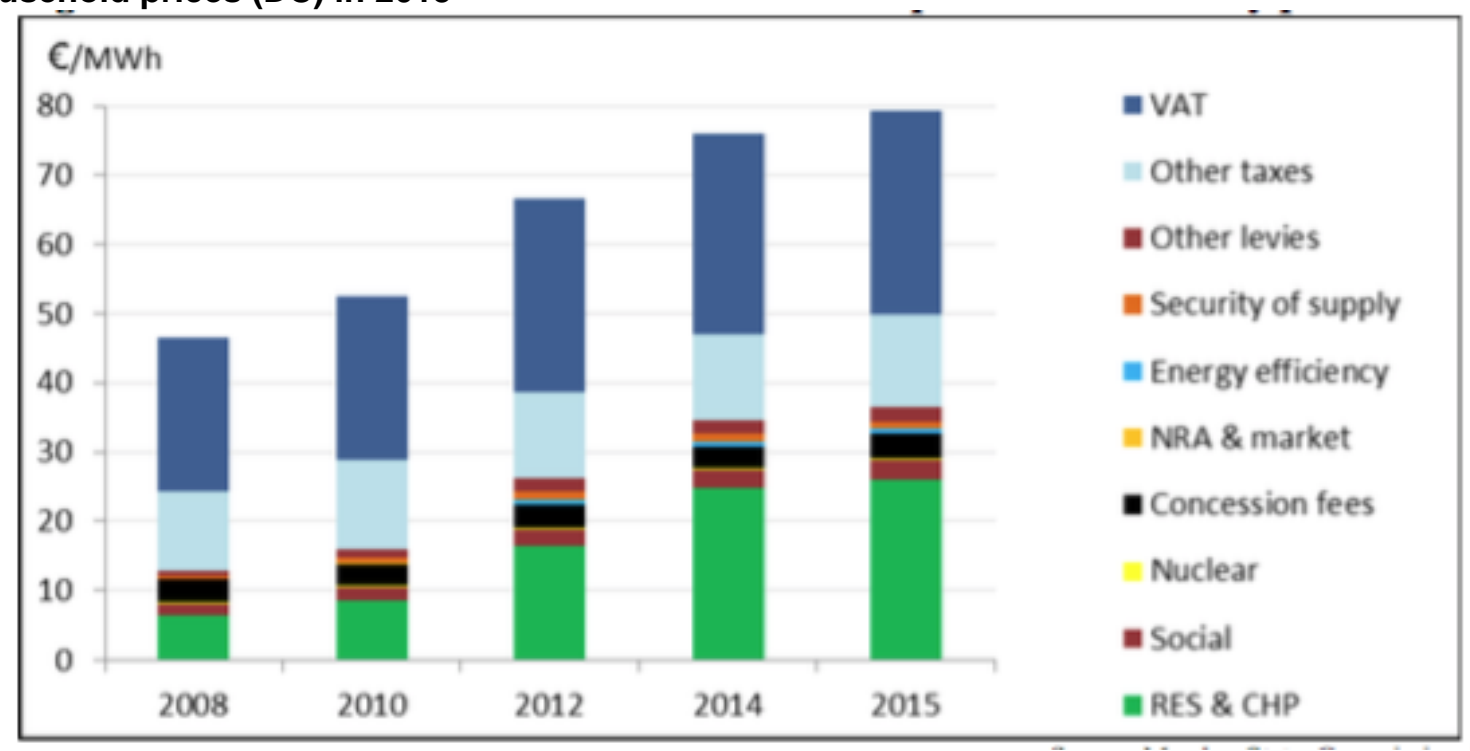

Source: EC (2016b), page 7.

A similar trend applies to electricity prices for industrial consumers (EC 2016b, pages 7-10). Between 2008 and 2015, prices increased by between 0.8 and 3.1 per cent per year, depending on the customer category. The share of taxes and levies rose from 12 to 32 per cent of the final price. These prices are subject to a variety of national subsidies and exemptions, making it very difficult to assess what consumers actually pay, especially for the largest energy intensive consumers. ${ }^{21}$ According to the EC, industrial electricity prices in 2015 were competitive against Japan, Brazil, and Turkey, but not against the USA, China, and Russia. Even though Member States typically find ways to support the largest companies, these levies will be a problem for companies that cannot escape them. Furthermore, the fact that some companies are exempted and others not and that the rules vary from one country to another introduces economic distortions and raises questions about whether the rules amount to illegal state aid. There is a case for greater transparency and homogeneity in the charging of levies and taxes to industry within the European Union. A first step on that road has been taken - the EC is now publishing statistics that compare the treatment of taxes and levies in different Member States.

While EU electricity prices for all consumers have been rising due to increases in taxes and levies, demand for electricity has fallen. As a reflection of the decline in demand, the level of net electricity generation in 2014 was 5.7 per cent lower than its peak level of 2008. The pattern observed for the EU28 (falling electricity generation over the period covering 2010-14) was reproduced in the majority of EU Member States; there were relatively large contractions in electricity generation in the United Kingdom, Spain, Italy, Belgium, the Netherlands, and Finland. ${ }^{22}$ There are many reasons for the decline; the recession is certainly one, with legislation to improve efficiency standards being another. Nevertheless, it is very likely that rising electricity prices were part of the explanation. Indeed, higher prices are consistent with the objective of encouraging more efficient use of energy. The problem, however, is that electricity competes with fossil fuels and is losing competiveness against the latter, partly as a result of differential fiscal treatment.

\footnotetext{
${ }^{21}$ From an economic efficiency perspective the production side should be exempted from these taxes. But of course economic efficiency is in conflict with equity considerations.

22 'Electricity production, consumption and market overview', Eurostat, June 2017, http://ec.europa.eu/eurostat/statisticsexplained/index.php/Electricity_production,_consumption_and_market_overview.
} 
In short, since 2008, electricity taxes, levies, and prices have been rising, and electricity demand has fallen. The rising levies are mainly each government's way of financing the cost of supporting renewable power to meet the EU target for renewable energy as a percentage of total energy demand. The renewables target is part of a broader EU policy to decarbonize the economy and to fight climate change. Electricity consumers are thus essentially financing a broader EU policy of supporting renewable energy and fighting climate change.

\subsubsection{Natural gas prices, taxes, and levies}

Natural gas prices can also be disaggregated into three components: energy, networks, and taxes and levies, as shown in Figure 9 (EC 2016b, pages 10-13). For retail consumers, household gas prices have increased since 2008 by almost 2 per cent per year, significantly less than for electricity. The energy component increased by 0.3 per cent per year between 2008 and 2015; it has experienced significant variations but has fallen over the last few years. Over the same period, the network component of average household prices has increased annually by 2.5 per cent per year, while taxes and levies have increased by 4.3 per cent per year. General taxes explain the rise of the 'taxes and levies' component, which in any case is lower than this component for electricity. There is a wide range of household prices in the EU, mainly reflecting different taxes and levies. Sweden, the Netherlands, and Denmark, for instance, have relatively high taxes and levies in their gas prices.

Figure 9: Components of average EU household retail natural gas prices, 2008-15

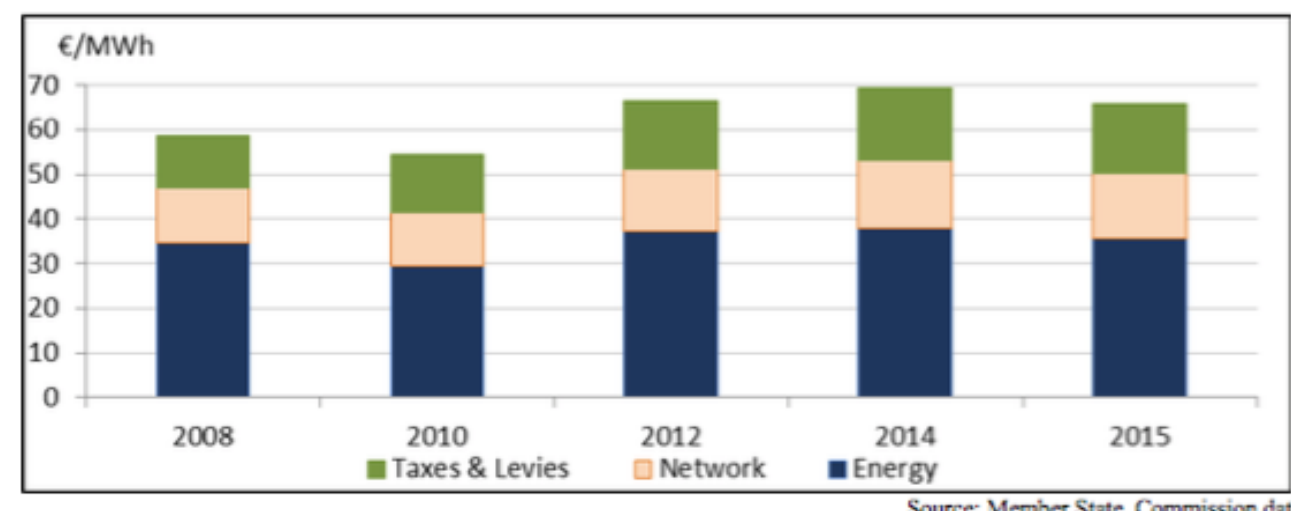

Source: Member State, Commission data collection

Source: EC (2016b), p. 11.

Average final prices for natural gas for industry in the EU in 2015 were actually below those of 2008 . This is explained by the energy component, which accounts for most of the industrial gas price and reflects international gas markets, whose prices have been falling since 2012. Taxes and levies account for only 8 per cent of industrial prices. As a result, there is relatively little differentiation in industrial gas prices across the European Union. Furthermore, there has been significant convergence in gas prices around the world. Nevertheless, international differences are still important. EC (2016b) reports that EU gas prices for industry in 2015 were two and a half times US gas prices, four times the price in Russia, and about half the price in Japan.

Demand for natural gas in the European Union has fallen over the period. This decline is almost entirely explained by a fall in the electricity demand for natural gas, resulting from a decline in overall demand for electricity and because natural gas has been displaced by renewables and (in some countries) by coal. The loss of market share to coal is explained by the relatively low prices of coal compared to natural gas, and by the very low price of $\mathrm{CO}_{2}$ emissions in the EU ETS.

In sum, natural gas has followed a similar pattern to electricity, in the sense that taxes and levies have risen, while demand has fallen (especially demand for natural gas for electricity). However, the size of levies in final prices is less significant for natural gas than it is for electricity. 


\subsubsection{Petroleum product prices and taxes}

EU average oil product prices reflect world oil prices as well as exchange rates and excise duties, which represent a large proportion of final prices in most EU countries. In spite of duties and the exchange rate effect, gasoline and diesel consumer prices (including taxes and duties) fell by 24 per cent and 28 per cent respectively, between the end of June 2014 and mid-February 2016, when prices were at their lowest level since 2009 (EC 2016b, page 14). This has encouraged rising demand for oil products in the EU.

A key point is that taxes and levies on gasoline and automotive diesel have varied little since about 2000, as reflected in Figure 10, and have not notably increased in response to the adoption of EU policies with respect to climate change. Although taxes vary by country, the EU Environment Agency argues that these taxes have not been widely used as an environment policy measure.

The extent to which fuel taxes have been used to internalise environmental externalities has not significantly changed during the period in question. Taxes on transport fuels have not been widely used in Europe as an environmental policy measure that can directly influence transport demand levels. Such a tax would reduce the environmental harm caused by the sector. ${ }^{23}$

Figure 10: Consumption-weighted average rates of real fuel taxes in EU-13 and EU-15 from 1990-2015

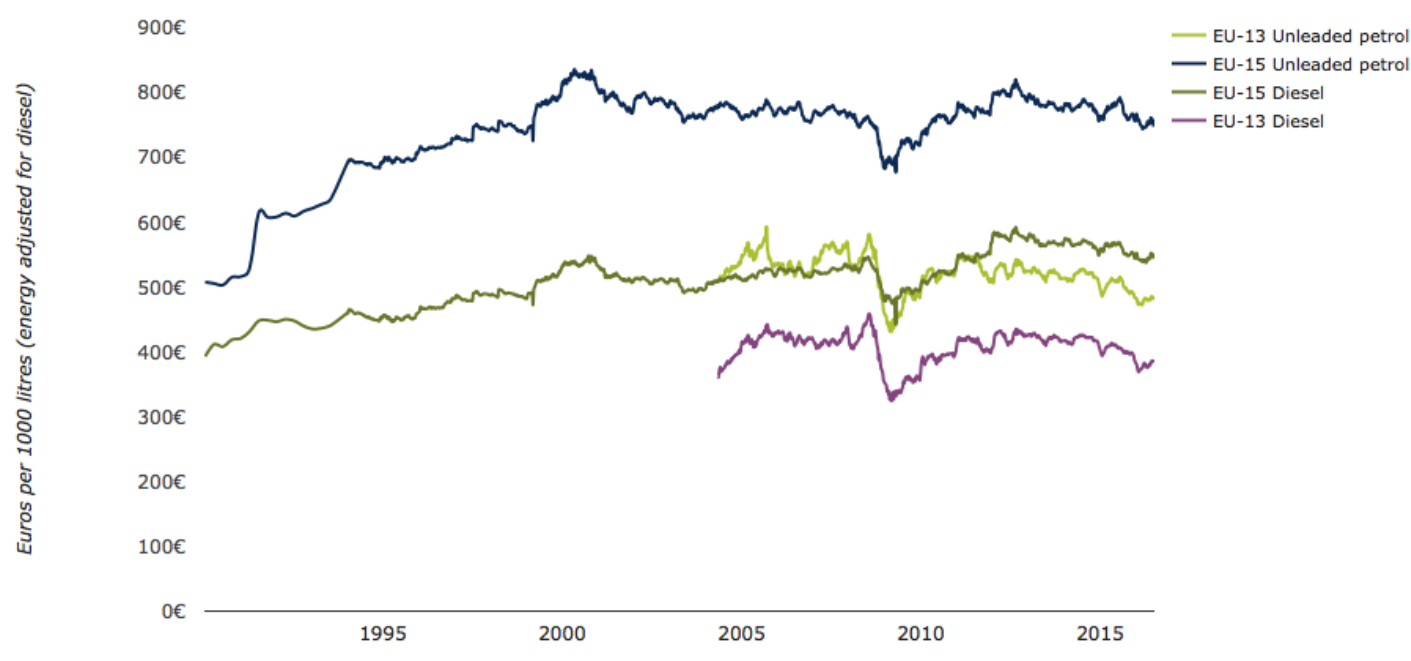

Source: EEA (2016c).

It could be argued that high fuel taxes on petroleum products internalize some of the related environmental externalities. However, it is noticeable that the revenue from these taxes has not changed much since 2000, whereas levies on electricity and, to a lesser extent, gas have risen substantially since the EU and the Member States began to promote decarbonization. The EU Environment Agency's view that excise taxes on transport fuels have not been widely used as an environment policy measure is consistent with the argument that these taxes were introduced for other reasons - including raising revenue to help to fund public investment and maintenance of the road system. It is worth emphasizing that some countries, such as Sweden, have introduced economy-wide $\mathrm{CO}_{2}$ taxes, in addition to their excise taxes, and these appear to have encouraged the decarbonization of heat and transport. This suggests the need for country-specific analysis of taxation of petroleum products before conclusions are drawn about the extent to which environmental externalities related to these products have been internalized.

\footnotetext{
23 'Transport fuel prices and taxes', European Environment Agency, 1 December 2016, https://www.eea.europa.eu/data-andmaps/indicators/fuel-prices-and-taxes/assessment-6/\#are-fuel-prices-leading-to-decreased-pressures-on-the-environment.
} 
It is also notable from Figure 10 that taxes on petroleum products in the EU are higher for gasoline than for diesel. This has contributed to a shift towards diesel; in 1980, petrol represented about two-thirds of fuel sales, but since 2013, diesel has accounted for about 75 per cent of fuel consumption by weight. This shift occurred in spite of the evidence that the external costs to the environment are higher for diesel than for gasoline. Although diesel engines are more efficient than petrol engines (and emit less $\mathrm{CO}_{2}$ ), they emit higher levels of air pollutants, in particular nitrogen dioxide and fine particulates. ${ }^{24}$ Taxation has not adequately captured the externalities of diesel.

The fossil fuel industry also benefits from various subsidies. The European Commission's studies on energy costs and subsidies in Europe found that government interventions and subsidies to the energy sector (excluding transport) amounted in 2012 to $€ 113$ billion, of which $€ 17.2$ billion was for direct fossil fuel subsidies to electricity and heating. ${ }^{25}$ In addition, it estimated that there were subsidies of $€ 24.7$ billion for fossil fuels in transport, although it was unclear what was included in this figure. Whereas it is appropriate to tax fossil fuels for their negative environmental externalities and not to subsidize these fuels, subsidies for renewable energy are usually justified on the grounds that they create positive environmental externalities.

In sum, taxes, levies, and prices have been rising for electricity, largely to pay for decarbonization resulting from the penetration of renewable power. On the other hand, prices for petroleum products are falling and are still supported by subsidies in some cases. Furthermore, excise taxes on oil products have not risen significantly since around 2000 and do not adequately reflect environmental externalities, especially in the case of diesel.

\subsubsection{Fiscal policy slowing decarbonization}

The fiscal policy framework for energy in the EU could slow decarbonization in three ways. First, it could slow electrification by penalizing electricity in comparison to fossil fuels, especially oil products.

Second, taxes and levies can introduce distortions into electricity markets, especially if they are collected through volumetric charges on energy sales (per kWh). Looking at investment incentives, if electricity consumers can avoid paying levies and fixed costs by reducing their consumption from the system, they have an incentive to self-generate even when it is less expensive to produce the equivalent electricity from the system. This raises the cost of decarbonizing the electricity system and can leave other consumers paying more. Looking at consumption signals, the taxes and levies collected through volumetric charges can discourage consumers from increasing their demand when wholesale prices are low, for instance when intermittent renewables are operating. Since demand flexibility is precisely what is required to integrate renewables, the collection of taxes and levies in this way raises the cost of further penetration of renewables.

Third, successful energy decarbonization requires consumer and popular support. Prices should reflect the long-run cost of an efficient and decarbonized electricity system. However, increasing electricity prices above those levels, in order to finance a variety of public policies, can create consumer dissatisfaction with the electricity sector, the government, and with the process of decarbonization. This can trigger populist responses, including the adoption of price caps and other measures that undermine liberalization and the innovations required to develop new low-carbon solutions.

\subsubsection{German illustration}

Germany offers an interesting case study of how fiscal policy can discourage decarbonization. A recent study commissioned by Agora Energiewende ${ }^{26}$ concluded that current energy levies and surcharges in

\footnotetext{
${ }^{24}$ Ibid.

${ }^{25} \mathrm{Ibid}$ (page 18) The $€ 17.2$ billion includes subsidies for coal of $€ 9.7$ billion and for gas of $€ 6.6$ billion.

26 'Cheap Heating Oil, Pricey Electricity: Current Levies and Surcharges Hamper Clean Energy Transition', Agora

Energiewende, 18 April 2017, https://www.agora-energiewende.de/en/press/agoranews/news-detail/news/cheap-heating-oilpricey-electricity-current-levies-and-surcharges-hamper-clean-energy-transition-3/News/detail/.
} 
Germany are inconsistent with a clean energy transition for some of the reasons mentioned earlier in this section.

The Agora study examines the extra charges that are added to different energies. It finds that taxes, levies, fees, and surcharges per kWh are 0.6 cents for heating oil, 2.2 cents for natural gas, 4.7 cents for diesel, 7.3 cents for gasoline, and 18.7 cents for electricity. The higher the penetration of renewable energy in the power system, the higher the levies on electricity, and the less competitive it is in comparison to the fossil fuels used in transportation and heating markets. It is worth reiterating that the EU's renewable targets refer to the demand for all types of energy, and that the policy focus has been on electricity because that is where renewable energy can be delivered at least cost.

While the decarbonization of electricity has been funded through the renewable energy levy (EEC), CHP surcharges, and higher network fees, the 'early 2000s environmental tax reforms on heating oil, natural gas, petrol and diesel have completely gone up in smoke', according to the summary of the report. The result is that German prices for heating oil, natural gas, gasoline, and diesel are cheaper than the European average and lower than five years ago, while electricity prices have risen significantly.

The report concludes the following.

The current system of levies and surcharges for promoting renewables is not fit for the challenges posed by the energy system of the future, and needs to be reformed. At present, the prices paid by end customers do not reflect the flexibility requirements of an energy system with a large share of renewables. Furthermore, electricity is at a disadvantage as a source of energy for the heating and transportation sectors, as end-customer prices for electricity are considerably higher than that for natural gas, heating oil and fuels, due to green energy levies and surcharges. ${ }^{27}$

The Agora report makes a number of recommendations, including shifting the EEC surcharge to the federal budget or to a separate fund. Weale (2016) and Robinson (2015 and 2016) have expressed similar concerns about a number of EU countries where they have identified inconsistency regarding rising levies on electricity and a long-term strategy of decarbonization through electrification. Both have also suggested the need for reform, including the proposal to spread the costs of financing renewables more widely. The Agora report also recommends changing the way in which remaining levies are collected so as to encourage greater demand flexibility, for instance by varying the levy to reflect wholesale market prices.

The German example is illustrative of a problem that almost certainly exists in other Member States with high taxes and levies on electricity, and where taxation of fossil fuels does not adequately internalize environmental externalities.

\subsection{The UK case of decarbonization of heat - electrification versus greening gas ${ }^{28}$}

The Swedish case looked back at the successful decarbonization of heat via electrification in a country with ample hydro (and biofuel) resources and very little domestic natural gas production or consumption. The UK case study looks forward, to understand the challenges of decarbonizing heat in a country where natural gas is the primary energy resource for heat. It illustrates the costs and the limits of electrification as a strategy for decarbonizing heat, and raises questions about the role of markets and fiscal policy in meeting decarbonization goals.

\subsubsection{The choice between electrification and the greening of gas}

Initially, on a cursory view, the expectation in the UK was that the heat market would be decarbonized through improved energy efficiency and the installation of heat pumps. However, in view of the very

\footnotetext{
27 'Green-Energy Levies and Surcharges', Agora Energiewende, 2017, https://www.agora-energiewende.de/en/projects/agothem-/Projekt/projektdetail/152/Abgaben+und+Umlagen/.

${ }^{28}$ See Annex 2 for the case study by Malcolm Keay on decarbonizing UK heat.
} 
ambitious UK emission reduction targets, the government and many others have been taking a new look at the alternatives. The new focus has concentrated minds and led to a number of studies arguing that 'greening gas' may be a preferable route.

The electrification of heat would require a significant increase in both the electricity network and generation capacity in order to meet peaks. The search has therefore been on to assess the alternatives.

- Natural gas is the main fuel for heating and replacing that heating system will be disruptive and expensive. A well-developed gas distribution system would be completely stranded if heating was entirely electrified.

- There is very little district heating in the UK (2 per cent of UK heating demand) and retrofitting large areas is prohibitively expensive, especially due to the extensive housing patterns - the preference for houses over apartments.

- Biomass heating is an option, but it currently makes up only 3 per cent of UK energy supply and there are serious questions about its sustainability and environmental impact.

- Energy efficiency will be an important part of the strategy, but the speed with which the UK housing stock can be retrofitted, and the costs of getting to zero-carbon housing, severely limit the contribution that it can make in the medium term.

The debate in the UK appears, at this stage, to be between decarbonization of heat using the electricity network or the gas network, or some combination of the two. The challenge for electrification is that the peak gas demand (primarily a reflection of the peak demand for heat) is significantly higher than the peak electricity demand and is much more variable through the year. ${ }^{29}$ Heat pumps and improved energy efficiency would reduce the strain on the electricity system, but the strain and the additional cost would be substantial. Furthermore, heat pumps may change the consumer experience; for instance, if heat pumps did not provide heat as quickly as consumers want it, consumers could well seek additional means of boosting peak heat. Moreover, the electricity system will require enormous storage capacity or other sources of flexibility (such as demand response) to deal with the variability of heat demand; this would be in addition to the challenges already presented to deal with intermittent wind power. By contrast, it is very inexpensive to store natural gas. Whereas battery storage costs about $\$ 200 / \mathrm{kWh}$ (and may fall to $\$ 100 / \mathrm{kWh}$ ), gas storage costs about 30 cents $/ \mathrm{kWh}$.

As the problems associated with electrification become more apparent, there has been an interest in exploring alternatives that use the existing gas network. Although in principle this could involve a number of options - including biogas, synthetic natural gas, or hydrogen from electrolysis - the use of steam reforming to convert methane to hydrogen, allowing the $\mathrm{CO}_{2}$ generated to be sequestered using CCS technology, has emerged as the front runner.

One study of a particular project to supply Leeds looked at issues of pipeline safety and capacity, broad cost estimates, and availability of CCS technology; it concluded that this option was feasible, both technically and economically. There are many specific advantages of this approach in the UK, not least the fact that hydrogen could continue to use the existing gas pipeline network, and also because hydrogen might provide a source of storage for the electricity system as well as for heat. These advantages, as well as the many challenges, are discussed in Annex 2.

\subsubsection{Relevance of fiscal policy}

The conclusion of the case study in Annex 2 is that, in the UK at any rate, the role of fiscal policy in relation to the decarbonization of heat will be ancillary rather than central. Some distortions could certainly be removed by a rebalancing of fiscal policy, but the latter would not deliver the scale of emissions reductions to which politicians are committed. Governments will intervene directly to deliver

\footnotetext{
${ }^{29}$ There is debate about the difference between peak heat and peak electricity. See for instance this blog for the view that the difference has been exaggerated: 'Is the "peak heat" issue all it's made out to be?', Exeter Energy Policy Group blog, 10 July 2017, http://blogs.exeter.ac.uk/energy/2017/07/10/is-the-peak-heat-issue-all-its-made-out-to-be/.
} 
decarbonization of heat, as they did with the promotion of renewables. Indeed, the case study argues that government intervention will have to be even greater in order to deliver the hydrogen strategy.

Whether or not one agrees with that conclusion in the annex, it is still important for fiscal policy to be aligned with decarbonization, and for it not to discourage electrification. The author of the main report supports the view that electrification could well play an important role in the decarbonization of heat and transport in the UK, even if that role was more limited than had initially been suggested. It is worth noting that British Gas recently attributed a 12.5 per cent increase in its standard electricity tariff largely to the rising cost of public policies, ${ }^{30}$ in line with the view that fiscal policy could be discouraging electrification.

A rebalancing of the fiscal burden for decarbonizing the system, which is at present borne almost exclusively by electricity consumers through taxes and levies, would help create a more level playing field. For instance, Newbery (2015) has recommended that financial support for renewables in the UK be shifted to the government budget, to be recovered through an increase in VAT (currently 5 per cent for electricity and gas, compared to a standard VAT rate of 20 per cent). An alternative would be for the financial support for renewables to be recovered through a tax on the sale of all energies, not just electricity. This rebalancing would help the relative attractiveness of electric heat pumps and electric vehicles. Although the Treasury has not yet followed that advice, it has recently introduced fiscal reforms that level the playing field between electricity purchased from the system and from decentralized energy resources. It did so by applying a 5 per cent VAT rate (down from 20 per cent) on battery storage for households installing a storage system alongside a new solar PV system. ${ }^{31}$ Although it can be argued that this VAT rate is distortionary and should be raised to the standard 20 per cent VAT rate for all energy (as suggested by Newbery), the point to stress here is that fiscal reform is levelling the playing field for alternative low-carbon energy sources.

These sorts of fiscal reforms help to encourage competition among alternative low-carbon energy resources and should be encouraged. Even though electrification may not play as great a role in the UK as many people originally thought, a level fiscal playing field will enable electricity to support decarbonization efficiently.

\subsection{Conclusion}

Fiscal policy is penalizing electricity and could discourage decarbonization through the electrification of transport and buildings, thereby raising the cost of meeting emission reduction targets. This fiscal barrier should be removed and proposals for doing that include spreading the levies to support renewable energy - for instance, passing these costs to the government budget to be recovered through VAT or in other ways. However, even if this fiscal distortion were removed, electrification is only one of the options for decarbonizing end markets and may be more expensive than alternatives, especially in countries with a high penetration of natural gas or in markets, such as maritime transport, where electricity may not be the least cost solution. To encourage competition among alternative low-carbon technologies, fiscal policy reform should be neutral with respect to the options that will contribute to the clean energy transition.

\footnotetext{
${ }^{30}$ On 3 August 2017, British Gas published figures claiming that the cost of government policies on electricity bills would hit $£ 165$ per household next year, up from £81 in 2014, while wholesale electricity costs would fall from £170 to £134 over the same period. (Cornwall Insight, Daily Bulletin, 4 August 2017.) 


\section{A framework for thinking about fiscal policy for energy}

This section of the report outlines a framework and proposes guidelines for assessing and reforming fiscal policy for energy. It begins by defining the focus and limiting the scope of the framework. It then introduces nine proposed guidelines that would enable the alignment of energy sector fiscal policy with environmental goals and, in particular, with decarbonization objectives for transport and buildings.

\subsection{Focus and scope of the framework}

Many experts and international organizations recommend tax reform in order to align fiscal policy with environmental goals. ${ }^{32}$ These recommendations usually emphasize the potential to raise additional revenue, capture rents that will otherwise go to oil and gas exporters, provide stronger incentives to use energy efficiently, and make polluters pay the social costs of their emissions. These are important issues, but they are touched on only tangentially, or not at all, here.

The proposed framework in this section concentrates on addressing inconsistencies in the fiscal treatment of different energies (fossil fuels and electricity) that may discourage efforts to decarbonize markets (transport and buildings in particular) that rely heavily on fossil fuels. This problem is becoming more important for two reasons. First, as explained earlier in this report, decarbonization efforts now need to focus more on transport and heating. Second, different energies need no longer be kept in separate silos (such as: liquid fuels for transport, gas for heating) because they can now compete in end markets. Competition among low-carbon energies can encourage innovation and reduce the cost of decarbonizing heating and transport. Fiscal policy should support such competition and certainly not penalize any potential decarbonization options.

The framework's scope is limited in three respects. First, it focuses on establishing a level fiscal playing field for low-carbon energies to compete in the transport and buildings markets, with the primary aim of meeting greenhouse gas emission targets at the lowest social cost, as well as improving local air quality as a co-benefit. It does not analyse other policies and regulations (such as those relating to issues like energy efficiency, sustainable mobility, energy performance of buildings, among others) for achieving environmental objectives, other than to stress the importance of consistency among fiscal and environmental policies. Nor does it look in detail at fiscal reforms aiming to achieve other important policy objectives.

Second, it concentrates on the incidence of taxes and levies on final prices paid by end consumers. The aim here is to analyse the signals being sent to consumers through final prices and to minimize distortions introduced by taxation.

Third, the framework focuses on fiscal reform for the energy sector, with the goal of a better alignment of tax signals with environmental objectives. It does not analyse comprehensive environmental tax reform or propose optimal fiscal reform for the entire economy. Nevertheless, it is guided by the objective of taxation theory, namely to design and implement taxes that minimize distortions in the economy and correct distortions related to negative externalities. Furthermore, it supports the general principle of fiscal revenue neutrality, whereby additional revenues from one tax are compensated by lower taxes elsewhere, and where lost tax revenues are recovered by raising other taxes, with compensation occurring either within the energy sector or elsewhere in the economy. And it recommends that fiscal reform for energy be introduced as part of a comprehensive fiscal reform package.

${ }^{32}$ For a summary of European experience with environmental tax reform, see EEA (2016b). 
The remainder of this section summarizes the framework by reference to the nine proposed guidelines that would enable fiscal policy to be aligned with efficient decarbonisation and improved air quality.

\subsection{Minimize distortions through technology neutrality}

With the exception of Pigouvian taxes on negative externalities, which are discussed below, taxes almost always introduce inefficiency into the economy because they create a wedge between costs and prices, thereby distorting price signals. The aim of fiscal policy should be to raise the revenue required to fund government expenditures with the minimum distortion to the productive process. ${ }^{33}$ The author's interpretation of this principle includes the idea that fiscal policy should minimize distortions to competition among alternative energy products. In other words, fiscal policy should enable effective competition between low-carbon electricity and other low-carbon energy options.

The best way to achieve that is for fiscal policy to be 'technology neutral', allowing price signals and markets to promote innovation and efficient (least cost) decarbonization. This is not just a theoretical construct; we have seen in this report how Sweden adopted this approach and followed it to a large extent.

The first proposed guideline is that fiscal policy for the energy sector should be technology neutral, with the caveat that negative environmental externalities are internalized.

\subsection{Tax negative environmental externalities (Pigouvian taxes)}

There is one exception to the rule that taxes distort markets, the issue of externalities:

- negative externalities, such as the effects of greenhouse gases and local pollutants;

- positive externalities, for instance from learning spillover effects related to support for renewable power.

Technology neutrality begins by establishing the basis for dealing with externalities, however they are produced. Negative environmental externalities should be charged via taxation of emissions. Where this is not possible, positive externalities should be compensated via subsidies. Although carbon emissions are not the same as air pollution in terms of their effects, the proposal here is to tax carbon emissions as well as emissions contributing to air pollution.

\subsubsection{Economy-wide taxation of air pollution and other externalities}

The case for taxing air pollutants $\left(\mathrm{NO}_{x}, \mathrm{SO}_{2}\right.$, particulates, others) is that they affect health and welfare today, especially in the places where the pollution is occurring. The external costs of these emissions are substantial. They are also amenable to local or regional solutions, including taxation, subsidies, or other measures, such as bonus-malus regimes, which were mentioned in the Swedish case study.

EU-wide performance standards for air pollutants from the power sector already exist, specifically through the Large Combustion Plant Directive and the Industrial Emissions Directive. These directives impose a cost, especially on coal-fired power stations that wish to continue operating. There are EUwide emissions standards for heating fuels and vehicles, and in some cases there may be local regulations. There are some instances (such as Sweden) where these pollutants are directly taxed or penalized, but in many other countries this is not so.

In line with the principle of the 'technology neutral' approach, the aim should be for air pollution and other negative externalities (such as water pollution) to face the same fiscal burden throughout the economy, regardless of where the emissions occur and what energy is responsible.

\footnotetext{
${ }^{33}$ See Newbery (2015) and Mirrlees et al. (2011).
} 
The second proposed guideline is that gasoline, gasoil, diesel, and natural gas used in heating and transport should bear the same fiscal burden (relating to, for example, each unit of emission) for their contribution to air and other pollution, as electricity does. Negative environmental externalities should be charged via taxation of emissions. This fiscal burden should reflect the social costs of the externalities caused by each of these energy sources. Where this is not possible, positive externalities should be compensated via subsidies.

\subsubsection{Economy-wide carbon taxes/prices}

Climate change is sometimes considered the perfect global environmental externality. Clean air and a stable climate are examples of public goods; these are goods that a person can use without reducing the quantity available for others, and others cannot be excluded from using the good. ${ }^{34}$ Like other public goods, they suffer from the problem of freeriding: since everyone benefits from the solution, there is an incentive to let others do the work. Carbon prices (through a cap-and-trade emissions trading scheme, for example) or taxation are a means of imposing a user fee to limit the free rider problem.

In theory, a carbon price is a suitable fiscal policy to address decarbonization throughout the economy. ${ }^{35}$ An economy-wide carbon price/tax is technology neutral and should encourage efficient decarbonization. It would in principle be simpler to introduce and administer than regulatory interventions for many sectors, and be a less costly way of cutting emissions than subsidies. For instance, a carbon tax could be administered upstream to oil, gas, and coal, with the tax reflecting an agreed social cost of carbon. Energy suppliers will include the tax in the fuels they sell and this will influence the entire energy supply chain, encouraging switching to lower-carbon fuels as well as stimulating low-carbon innovation and investment, provided consumers are rational. The revenues could be recycled into the economy, for instance to compensate the most vulnerable consumers. Furthermore, if it were a credible long-term signal, it would provide a level playing field to influence investment that would drive down greenhouse gas emissions.

When it was introduced, the EU Emissions Trading System (EU ETS) was designed to generate spot and forward prices for $\mathrm{CO}_{2}$ emission allowances. These allowance prices would be costs for fossilbased electricity generation. In the short term, these prices were expected to be sufficient to enable natural gas to replace oil and coal in the power sector, because gas has a lower carbon content than the other two. In the longer term, they were expected to provide the necessary incentives for innovation and investment in decarbonized energy alternatives. Many, including the author, are of the view that this could have worked had the EU ETS been properly designed and if governments had allowed the EU ETS to work - neither of these conditions held and the emissions trading scheme has been a disappointment with respect to both short-term and long-term signals.

In practice, putting a price on carbon emissions has been problematic in the EU (and elsewhere) for a variety of reasons. First, it is very difficult to agree on the value of environmental externalities (the 'social cost of carbon'), especially when the externalities are global and affect future generations. Agreement is especially difficult when the system is badly designed to address the concerns of those being taxed, whether energy intensive industries, residential consumers, or others whose costs will rise. Second, to date, it has proven very difficult to establish a trading mechanism or carbon tax with sufficient long-term credibility to motivate low-carbon investments, and to set prices that are high enough to warrant investment in low-carbon technologies. Third, in the EU, many other measures have been introduced to encourage decarbonization or to limit emissions; these reduce the demand for emission permits and have contributed to lower prices in the EU ETS. One could argue that these additional measures were the reason why the EU ETS has not worked, but it is also fair to argue that governments wanted quicker results than markets could deliver. In any case, these other policy measures - and in particular government-sponsored financial support for renewable power - have been the main drivers of decarbonization. Fourth, the EU ETS covers large installations that account for about 45 per cent of EU $\mathrm{CO}_{2}$ emissions. It includes power stations and refineries, among other installations, but does not include

\footnotetext{
${ }^{34}$ Definition from Energy Education website: http://energyeducation.ca/encyclopedia/Public_good.

${ }^{35}$ Aldy (2013).
} 
transport or buildings, among other activities. Although $\mathrm{CO}_{2}$ prices are levied on these other sectors in some countries, in many countries carbon taxes or prices do not apply.

In spite of the challenges facing the establishment of credible carbon taxation/pricing for the longer term, support for carbon taxing is growing, including among oil and gas companies for whom carbon taxation is a means of weakening competition from coal. The EU is about to introduce a reform of the EU ETS that aims to improve its performance, but it may well not provide the necessary long-term signals to decarbonize. ${ }^{36}$

The third proposed guideline is to introduce an economy-wide carbon price/tax with a long-term rising floor price consistent with decarbonization objectives and with the social costs caused by the emissions. Where this is not possible, positive externalities should be compensated via subsidies.

In practice, introducing an economy-wide carbon price/tax with a rising floor would involve two steps in the EU:

- Member States should tax carbon emissions for activities that are not covered by the EU ETS, in particular transport, heating, and cooling. The carbon price should be equivalent inside and outside the EU ETS.

- The EU ETS requires a mechanism to ensure a rising floor price, possibly along the lines of the original UK mechanism - this amounted to a tax that applied whenever the EU ETS price was below the floor.

\subsection{Finance renewables and other public goods through general taxation}

Certain types of renewable power share the characteristics of public goods, for example solar power. In principle, no one can be stopped from using the sun and no one's use of the sun will limit the amount that is available to others. Some economists, including the author, argue that the extra revenue (in addition to revenues earned in the market) needed to finance renewables should come from general taxation. Newbery (2015) argues:

It thus follows that the revenue needed to finance renewables and other public goods should come from general taxation raised in the least distorting ways consistent with distributional objectives - either through income taxes or a uniform rate of VAT, and not by selectively charging single products like electricity.

This is an argument not only for financing renewable power, but also for supporting R\&D in low-carbon technologies, such as storage. If renewables and related research were financed in this way through the government budget, rather than through levies on electricity, it would both support innovation and lead to a reduction in costs that would not otherwise occur. It would also mean that no single energy (such as electricity) was bearing the cost of supplying renewable energy; it would also leave government to decide how best to recover the costs no longer collected through the electricity price.

The proposal to finance these costs through the government budget has some international precedents, in particular from the USA, where Federal and State governments have contributed to the financing of renewable energy, and other policy goals, through general taxation. The Czech Republic has recently passed some of the costs of financing renewables to the government budget, and there are debates about doing the same in Germany, Denmark, and Spain.

There are two main challenges to be addressed. First, if the result is to increase the government deficit, it will be necessary to replace the lost revenue. In that case, a transitional arrangement may be needed, for instance transferring the levies to the budget in stages. However, the deficit problem need not emerge, or would be less, if it is part of a comprehensive fiscal reform that includes additional revenues

\footnotetext{
36 'Reform of EU carbon trading scheme agreed', The Guardian, 28 February 2017,

https://www.theguardian.com/environment/2017/feb/28/reform-of-eu-carbon-trading-scheme-agreed.
} 
from other environmental taxes, and a sharing of the cost of financing renewables among all energy sources or through an increase in a broad-based tax like VAT.

Second, it could be argued that lower electricity prices will reduce the incentives for energy efficiency and energy conservation. This is an important issue, especially because lower electricity prices could lead to higher electricity demand and higher emissions for the economy. However, with continued decarbonization of electricity, these concerns become far less relevant.

The fourth proposed guideline is to raise the extra revenue needed to support renewable energy (and other public goods, including $R \& D$ ) from general taxation, in a way that minimizes distortions in the economy, for instance through higher VAT or income tax, or through a tax on all energies.

\subsection{Elimination of fossil fuel subsidies}

Subsidies for fossil fuels are increasingly under scrutiny. ${ }^{37}$ Subsidies reflect the difference between what a consumer pays and economically efficient prices - where the latter include the negative environmental externality in addition to the direct cost of the product. Producers receive subsidies, as do consumers (agriculture and fisheries in the EU, for example); in either case, subsidies result in higher demand for fossil fuels and lower demand for less carbon-intensive energies.

The fifth proposed guideline is that any remaining subsidies for fossil fuels be eliminated as soon as possible, both on the producer side and on the consumer side.

\subsection{Time to apply Ramsey logic}

The degree of inefficiency of the tax system depends on the elasticity of the demanded goods or services being taxed. To minimize inefficiency, optimal taxation (according to the ideas of Ramsey) implies higher taxes on the goods or services for which demand is most inelastic. This is because any decline in demand (and consequently in government revenue) related to a higher tax will be less than it would be if taxes were raised on goods and services for which demand was more elastic.

The Ramsey principle could justify a higher tax burden on the retail price of electricity and other energies than on non-energy products. The academic literature finds that energy demand is price inelastic: price increases on energy products give rise to a less than proportional reduction in demand and the response is less in the short term than in the longer term. Indeed, one the latest studies (Labandeira, 2017) finds elasticity estimates that are even lower than those from previous meta-analysis; this is ostensibly due to higher income and improved energy efficiency. Such findings might appear to justify even higher taxation of energy products.

However, current fiscal treatment of electricity is not consistent with Ramsey logic. For instance, if the extra cost of renewable power were to be recovered from all energy sources using Ramsey logic, the levies on electricity would fall and levies on the other energy sources would rise. Applying that logic to recover those costs from all sectors of the economy, or through an increase in VAT, would imply even lower levies for electricity. This is because the levies currently added to the electricity price recover virtually all of the extra costs, whereas Ramsey logic would share those costs more widely on the basis of demand elasticity.

Today's levies on electricity are not the consequence of Ramsey logic, but rather an instance of governments using electricity as a convenient tool for taxation, reflecting the fact that electricity is an essential good and that, until recently, consumers have had no choice but to buy the electricity delivered from the system. These levies conflict with decarbonization through electrification if they discourage a

\footnotetext{
${ }^{37}$ See for instance reference to a recent study on fossil fuel subsidies, quoted in The Guardian, 'Fossil fuel subsidies are a staggering $\$ 5$ tn per year’, The Guardian, 7 August 2017, https://www.theguardian.com/environment/climate-consensus-97-percent/2017/aug/07/fossil-fuel-subsidies-are-a-staggering-5-tn-per-year.
} 
shift to low-carbon electricity and favour instead fossil fuels. Furthermore, they are unsustainable to the extent that higher prices for electricity encourage consumers to disconnect, or switch to fossil fuels. Consumers have traditionally thought of energies in different silos: gas and fuel oil for heating, gasoline and diesel for transport, and electricity for lighting, electrical appliances, and static motors. As these silos begin to break down, consumers are more likely to factor in differential energy prices (along with other considerations) when making decisions about investment in heating systems and vehicles. Where current fiscal treatment of energy penalizes low-carbon electricity and favours fossil fuels, this discourages consumers from investing in electric solutions, and indeed may encourage consumers to switch from electricity to fossil fuels.

The sixth proposed guideline is that governments should consider using Ramsey logic to recover the extra cost of financing renewable power (and other public policies) from all energy sources or more widely (through VAT, for example).

\subsection{Consider distributional consequences}

Fiscal reform of the energy sector should recognize the distributional impact of rising taxes and prices for different energy products. The cost of electricity as a share of household income falls as income rises; this is a sign that poor people are especially affected by rising electricity prices, and benefit most from a fall in prices. The opposite is true for oil products because rising income is usually associated with more vehicles and passenger miles.

This is not just a matter of equity. It is also a matter of political sensitivity. The EU policy of putting consumers first implies that consumers will recognize benefits from the clean energy transition. In those countries where electricity prices rise, and where consumers see no direct benefit, the likely result is consumer and public dissatisfaction with the electricity sector and with government policies, including decarbonization. Governments can do a better job of informing consumers about the longer-term benefits of decarbonization, but increasing electricity levies to pay for decarbonization has a regressive distributive effect. This can easily feed populist reactions and could undermine decarbonization policies as well as efforts to further liberalize the sector.

The seventh proposed guideline is to consider carefully the distributional consequences of fiscal policy reform of the energy sector and to favour reforms that benefit the poorest and most vulnerable consumers.

\subsection{Recover levies and system costs in a way that minimizes distortion of electricity markets}

Taxes and levies on electricity should be recovered in a way that distorts investment and consumption decisions as little as possible. The same can be said for the recovery of the fixed costs of the electricity system, in particular network costs. In many cases, taxes, levies, and fixed system costs are paid on a volumetric basis, related to the amount of energy purchased from the system. In these cases, consumers may be able to avoid taxes, levies, and fixed system costs by self-generating, even though this could well be inefficient from the system's perspective and pass the fiscal burden to others. As mentioned earlier in the German case study, this approach to cost recovery can also be a barrier to demand flexibility, which is important for the integration of intermittent renewables.

It is also important to ensure that consumers are paying the incremental cost of energy. In the case of electricity, this should include network costs as well as the costs of wholesale energy and retail services. Network costs, especially distribution network costs, should reflect the cost of integrating distributed energy resources and electric vehicles. The wholesale energy costs should reflect the long-term costs of an efficient, decarbonized system. To the extent that taxes and levies are added to those network and energy costs, they distort price signals. Although the recommendation is to shift levies away from the electricity price, there will be some taxes and levies, as well as fixed costs, to recover. 

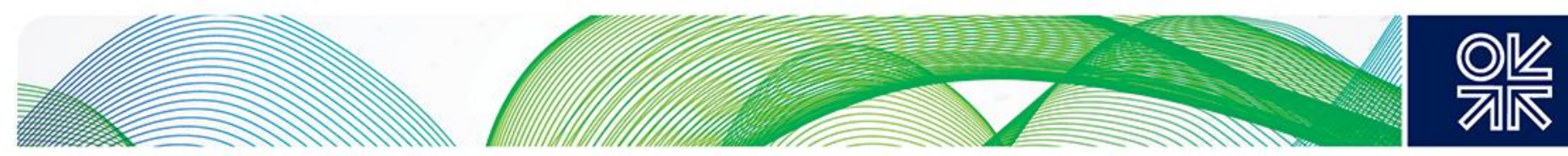

The eighth proposed guideline is that fiscal policy reform be accompanied by network and other electricity tariff reform to minimize distortions to investment and consumption.

\subsection{Comprehensive and revenue-neutral fiscal policy reform}

Fiscal policy reform of the energy sector should be part of a comprehensive fiscal reform aimed at eliminating existing tax distortions that slow economic growth and employment, while addressing distributional concerns that may result from specific tax reforms. This is consistent with the principle of revenue-neutral fiscal reform, which was introduced in the introduction to this section.

Fortunately, additional tax revenue from environmental taxation offers the opportunity for wider tax reform and for recycling the revenue. The Canadian province of British Columbia offers an example of how an economy-wide carbon tax could work. There, the government returns all carbon tax revenues to the economy by cutting corporate and individual tax rates and through means-tested tax credits. More generally, the idea is that taxation of a variety of emissions $\left(\mathrm{CO}_{2}, \mathrm{SO}_{x}, \mathrm{NO}_{x}\right)$ provides income that can be used to fund entitlement programmes and to reduce taxes (e.g. on labour) that are distorting the economy, as illustrated in the Swedish case study.

The ninth guideline is to make energy sector fiscal reform part of a comprehensive revenue-neutral fiscal reform that is aligned with environmental objectives, revenue generation, economy efficiency, and distributional impact, seeking ways to mitigate the consequences for those groups most negatively affected.

\subsection{Conclusion}

These proposed guidelines constitute the basis for aligning fiscal policy with the objectives of efficient decarbonization of transport and buildings and reduced pollution of other kinds. The aim is to eliminate the fiscal barriers to decarbonization and establish a level fiscal playing field so that all low-carbon alternatives have similar opportunities to contribute. 


\section{Conclusions and recommendations}

This report confirms that electricity is key to the clean energy transition, and in particular to the decarbonization of transport and buildings. It focuses on one specific barrier to electrification: fiscal policy that could put low-carbon electricity at a competitive disadvantage as a source of energy for transport and buildings. Levies on electricity in the EU have risen substantially since 2008 , primarily but not exclusively to finance renewable power development whose costs could not be recovered through markets. The higher the penetration of renewable energy in the power system, the higher the levies on electricity and the less competitive it becomes by comparison to the fossil fuels used in transportation and heating markets. It is worth remembering that the EU's renewable targets refer to the demand for all types of energy, and that the policy focus has been on renewable electricity because that is where renewable energy can be delivered at least cost. It makes little sense to penalize the main vehicle for decarbonization, especially when there is a broad policy consensus that electrification of transport and buildings is necessary to meet climate change policy goals. A central conclusion is the need to rethink how best to finance the extra costs (those that cannot be recovered through electricity markets) of renewable power and R\&D, for instance through general taxation (such as VAT or income tax) or by a tax on all energies.

A second conclusion is the need to tax environmental externalities throughout the economy, in particular to ensure that gasoline, gasoil, diesel, and natural gas bear the same fiscal burden for their contribution to climate change (and local pollution) as electricity does, and that taxes as far as possible reflect the social costs of the externalities. It could be argued that high fuel taxes on petroleum products internalize some of the related environmental externalities, while also meeting geopolitical and other policy objectives. However, it is noticeable that the revenue from these taxes has not changed much since 2000, whereas levies on electricity and, to a lesser extent, gas have risen substantially since the EU and the Member States began to promote decarbonization. The European Environment Agency's view that excise taxes on gasoline have not been widely used as an environmental policy measure is consistent with the argument that these taxes were introduced for other reasons, including raising revenue to help fund public investment and maintenance of the road system. This argument is particularly strong in the case of diesel, whose taxes are lower than those on gasoline, in spite of the evidence that the external costs to the environment are higher for diesel than for gasoline. It is time to review the fiscal burden faced by the different energy products in Member States, to ensure that fossil fuels are taxed to reflect fully their environmental externalities, wherever the emissions occur.

A third conclusion is that electrification of transport and buildings is a key strategy for decarbonization, but is not the only one. Each country will have its own set of decarbonization options, defined by history, fiscal policy, existing networks, customer experiences, and the costs and benefits of the options. Fiscal policy should aid each country to reveal and support the best options available. This report proposes guidelines for energy sector fiscal reform that are 'technology neutral'.

This last conclusion is relevant to the debate about whether governments should choose a specific lowcarbon technology path and support it actively through fiscal and other policies, rather than being 'technology neutral' in policy design. One side argues that time is short and that everyone must get behind the no-regret (or low-regret) option. For instance, this side maintains that the consideration of hydrogen-based systems could delay climate actions, such as housing stock retrofit and rolling out electric vehicles. The other side argues that markets work better than governments in making investment decisions and that competition among alternatives will force investors to sharpen their pencils and innovate, taking risks in return for the potential rewards. Time is indeed short and governments may choose to intervene to realize their decarbonization policy objectives. However, history shows how quickly technologies change and how easy it is for governments to choose the wrong technology, to overbuild, and for costs to get out of control, leaving consumers and taxpayers to foot the bill. This author favours allowing prices and consumer-driven markets to work as effectively as possible in promoting innovation and investment in low-carbon solutions. Governments will still have a role to play, in particular with respect to defining the long-term policy goals, the policy instruments for 

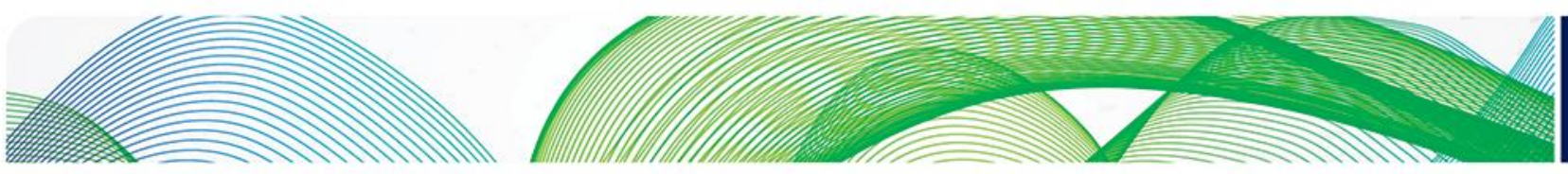

achieving them, and the allocation of risk and reward. Whatever role governments choose to play, they should not introduce fiscal policy distortions that unnecessarily raise the cost of decarbonization.

If consumers are to play a central role in decarbonizing the economy, it is critical that they receive price signals that reflect the incremental costs of the alternatives. Often, fiscal policy leads to distorted price signals. Fiscal policy can encourage the use of fossil fuels by not taxing the full cost of environmental externalities. Likewise, it can discourage socially efficient electrification of transport and buildings by raising the price of electricity to recover a variety of public policy costs. And it can encourage consumers to produce their own renewable electricity even when the economic cost is much higher than buying renewable energy from the system. Fiscal policy should avoid these and other distortions, allowing consumers to make decisions based on the incremental economic costs of the alternatives (including environmental externalities). Although this report has focused on decarbonization, fiscal policy should internalize other key externalities, especially those related to urban air pollution. Some countries have gone a long way towards introducing technology neutral and economy-wide environmental taxation. However, many countries have not done so.

Decarbonization policy has focused thus far on low hanging fruit, especially energy efficiency and renewables. We know that attention will need to move to other sectors but we don't yet have detailed and effective policies in place. Indeed, the need to decarbonize transport and buildings is clear from the European Commission's Clean Energy For All Europeans (EC 2016a). Fiscal policy is only one of the policy instruments that governments have at their disposal and it is often not the most important one. However, fiscal reform is a relatively easy and quick way of starting to move in the right direction and of reducing the risk of getting stuck with the wrong sort of investment that will lock in high carbon intensity. 


\section{References}

Aldy (2013). 'The Case for a US Carbon Tax', Joseph Aldy, Oxford Energy Forum, Number 91, February, 2013.

EC (2007). An energy Policy for Europe, European Commission, COM (2007) 1 Final, Brussels, 10 January 2007.

EC (2016a). Clean Energy For All Europeans, European Commission, COM (2016) 860 final, Brussels, 30 November 2016.

EC (2016b). Energy prices and costs in Europe, European Commission, (COM (2016) 769 Final), 30 November 2016.

EEA (2016a). Analysis of the key trends and drivers in greenhouse gas emissions in the EU between 1990 and 2014, European Environment Agency, June 2016.

EEA (2016b). Environmental Taxation and EU Environmental Policies, European Environment Agency, European Environment Agency, EEA Report No 17/2016, 6 September 2016.

EEA (2016c). Transport fuel prices and taxes, European Environmental Agency, 1 December 2016, https://www.eea.europa.eu/data-and-maps/indicators/fuel-prices-and-taxes/assessment-6.

Energimyndigheten (2017). Energiläget i siffror 2017, Eskilstuna.

EPA (2017). Nationella utsläpp och upptag av växthusgaser (national emissions and absorption for GHG), Environmental Protection Agency, (den 6th March), Hämtat från https://www.naturvardsverket.se/Sa-mar-miljon/Statistik-A-O/Vaxthusgaser-nationella-utslapp-ochupptag-1990-2015/ den 15052017.

ETC (2017). Better Energy, Greater Prosperity: achievable pathways to low-carbon energy systems, Energy Transmission Commission, April 2017.

EU (2011). 2050 Low-carbon economy (Energy Roadmap 2050), European Union, COM (2011) 885 final, Brussels, 15 December 2011.

Eurelectric (2017). A Bright Future for Europe: the value of electricity in decarbonising the European Union, Eurelectric, 2017.

Hawkins et al. (2012). 'Comparative Environmental Life Cycle Assessment of Conventional and Electric Vehicles', Troy R. Hawkins, Bhawna Singh, Guillaume Majeau-Betez, and Anders Hammer Strømman, Journal of Industrial Ecology, Volume 17, Number 1, 2012.

IEA. (2017). CO2 emissions statistics, Hämtat från https://www.iea.org/statistics/topics/CO2emissions/ from 14072017.

IPCC (2014): Climate Change 2014: Mitigation of Climate Change, Intergovernmental Panel on Climate Change.

Labandeira (2016). 'A meta analysis on the price elasticity of energy demand', Xavier Labandeira, Jose M. Labeaga, and Xiral López-Otero, European University Institute, EUI Working Papers, RSCAS 2016/25.

Mirrlees et al. (2011), Tax by Design, James Mirrlees et al., IFS, 13 September 2011. 

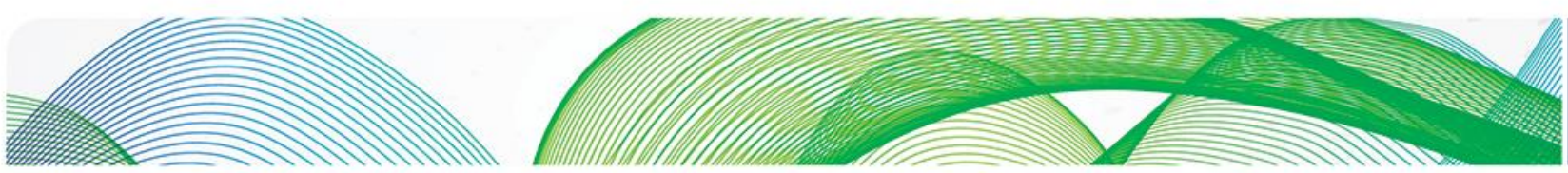

Monitor-Deloitte (2016). Un modelo energético sostenible para España en 2050 Recomendaciones de política energética para la transición, Monitor-Deloitte, marzo 2016.

Newbery (2015), "Reforming UK energy policy to live iwhtin its means", Cambridge Working Papers in Economics, September 14, 2015.

Robinson (2015), Análisis comparativo de los precios eléctricos en la Unión Europea y Estados Unidos: una perspectiva española, David Robinson, octubre 2015, Eurocofin.

Robinson (2016). 'A comparison of US and EU electricity prices: the relevance of the government wedge', David Robinson, Oxford Energy Forum, Number 104, February 2016.

Sandbag (2017). Energy Transition in the Power Sector in Europe: State of Affairs in 2016 Review on the Developments in 2016 and Outlook on 2017, Sandbag, Agora Energiewende, January 2017.

Sterner et al. (2013): 'Sweden's CO2 tax and taxation reform experiences', Thomas Sterner, Henrik Hammar, and Susanne Åkerfeldt, in R. P. Genevey, Reducing Inequalities: A Sustainable Development Challenge. TERI press.

Weale (2016). 'Decarbonization through electrification - the importance of energy taxation being in line with long-term energy policy', Graham Weale, Oxford Energy Forum, Number 104, February 2016. 


\section{Annex 138: Electricity and Decarbonization in Sweden ${ }^{39}$}

Electrification in Sweden started in 1876 in Gothenburg; electricity was already coming from small-scale hydro power at that point, and more and more run of the river hydropower generation was then developed in south and central Sweden. The first large-scale hydro power station in the country followed in 1893, and there was then a rapid exploitation of the major rivers in northern Sweden (Brandel, 2001).

Driven by the first (1973) and second (1979) oil crises, as well as the development of nuclear power which led to a massive surplus of electricity production, the Swedish heating and power sector experienced a decarbonization. The provision of heating moved away from fossil fuel use in two ways. One involved use of the excess supply of electricity for heating purposes all over the country. At the same time, district heating was promoted as a way to reduce dependence on oil. District heating, often in the form of CHP, became the dominant source of heating, especially in densely populated areas of Sweden, and it was heavily promoted by municipalities which owned energy companies.

During the period 1967-91 there have also been unsuccessful attempts to increase the use of natural gas in Sweden (often proposed as a bridge to a fossil-free future) and, later, biogas. Natural gas only plays a marginal role in the Swedish energy system, mostly on the Swedish west coast in the petrochemical industry. ${ }^{40}$

The country's nuclear programme consists of ten reactors (two in long-term shut down) built during the period 1971-85, with a total installed capacity of 9,531 MWh (in 2014). The first nuclear reactor, Ågesta, was finished in 1963 and terminated after ten years; it was actually planned to deliver both heat and electricity. ${ }^{41}$ The other ten Swedish nuclear reactors were all of either the boiling water or the pressurized water type and were located relatively far from densely populated areas; they were only designed to deliver electricity. At times, plans surfaced to connect one or another of the reactors to a district heating network but, unusually, those plans stumbled due to excessive cost. The four oldest reactors, beginning with the reactor Oskarshamn 1 in 2017, will be phased out by 2020. Nuclear power still produces almost 50 per cent of electricity generation.

Hydropower was already well developed in the early 1900s and amounts to almost another half of the country's electricity production. Thus, Sweden's heat and electricity generation was using only limited quantities of fossil fuels relatively early in its history.

The first district heating plant in Sweden was built in Karlstad 1948 when a thermal power plant was converted to a CHP plant (Werner, 2017). Several municipalities followed in the 1950s and today there are about 500 active district heating systems. District heating is currently the market leader in the heating market.

Figure A1.1 illustrates the Swedish energy use by carrier, showing both a huge increase in electricity use and district heating, as well as the decline of fossil fuels. Fossil fuels are largely used in the transport sector.

\footnotetext{
${ }^{38}$ This annex was written by Klaus Hammes, Chief Economist at the Swedish Energy Agency. The views expressed are his own and do not represent the views of the Swedish Energy Agency.

${ }^{39}$ The annex offers a short survey of those developments in Sweden that are deemed, relatively, the most important in giving a feeling for how the current situation has developed over time. The purpose of this annex is in no way intended to give a complete description, which would exceed the space available. For those interested in knowing more, Högselius et.al. (2007) and Sohlman (2013) are recommended reading.

40 Åberg (2013).

${ }^{41}$ Helldner et.al. (2008).
} 
Figure A1.1: Total energy use by energy carrier 1970-2016

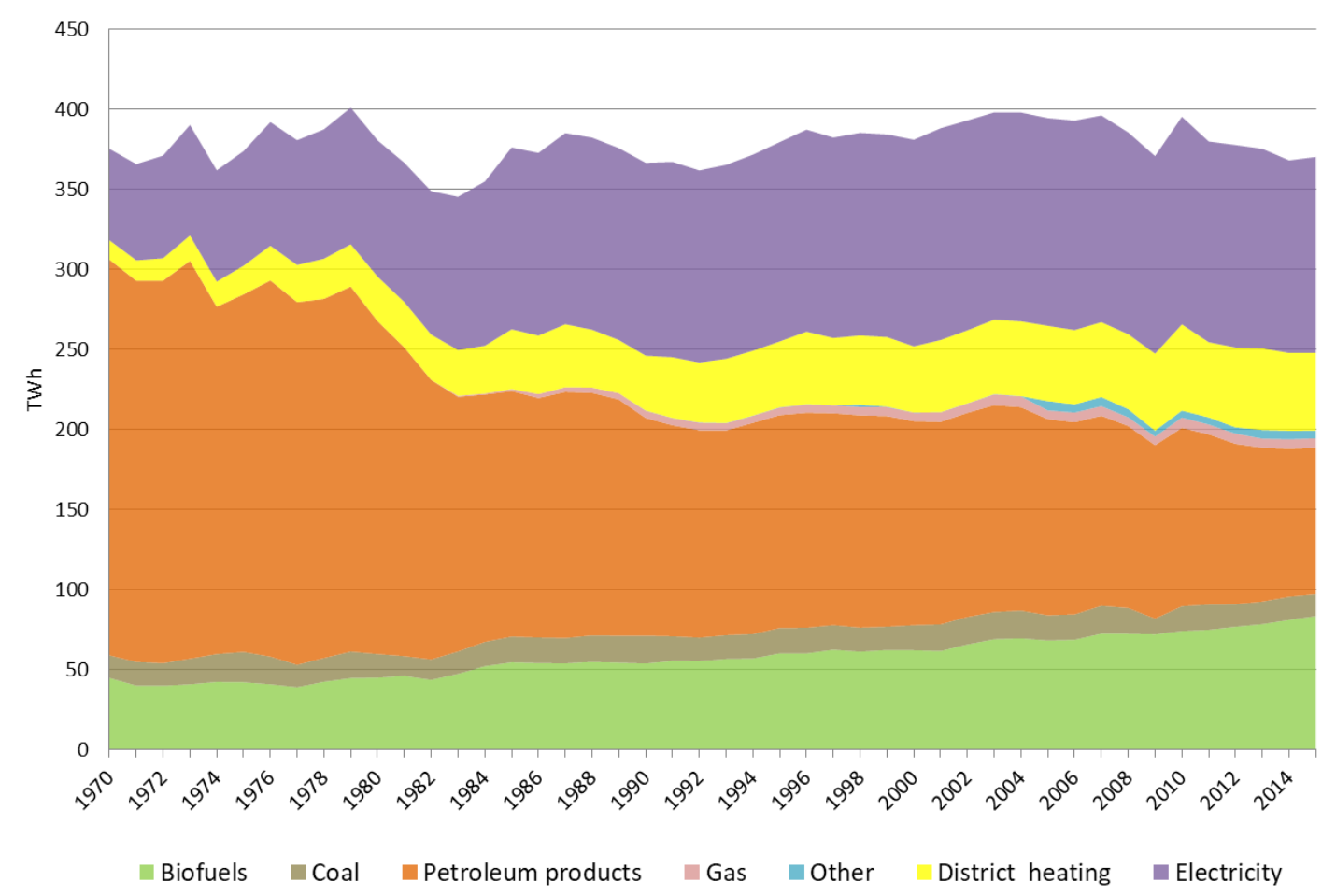

Source: Energimyndigheten, Energiläget i siffror 2017, 2017b.

Since the beginning of the 1980s the idea of a green tax reform (using environmental taxation to reduce negative external effects and using the income to reduce other taxes which had a negative impact on competition and employment) gained strength and was the focus of several government investigations. Sweden is nowadays often seen, and indeed promotes itself, as a leader on environmental issues and renewable policies (Ydersbond, 2014; Uba, 2010). Policies in the environmental sector in Sweden are usually based on the principle of technology neutrality, keeping options open, combined with welldeveloped funding for energy research and policies to remove various kinds of market failures.

In the period 1989-97 there were a number of government investigations (SOU 1989:21, (1989); 1989:83, (1989); 1990:59, (1990); and 1997:11, (1997)) into how to address environmental issues through green tax reform.

In 1991 a carbon tax was introduced; it taxed the carbon content of fuels. The tax generated around 2.4 per cent of total tax revenue (Bosquet, 2000), and it was increased stepwise to the current level of 1.13 $\mathrm{Skr} / \mathrm{kg} \mathrm{CO}_{2}{ }^{42} \mathrm{At}$ the same time, a sulphur tax was implemented. These taxes put a price on externalities but essentially left it to the market to find the optimal way to adapt to these taxes. Income from these environmental taxes contributed to a reduction in taxation of labour.

The idea of a green tax reform regained power in the late 1990s and the budgets for 2001 and 2002 contain tax increases for fossil fuels, with tax revenues used to reduce labour taxation (income tax and payroll tax). Thereafter the idea of a green tax reform faded out.

In 2016 environmentally motivated tax revenue amounted to Skr98 billion while direct subsidies amounted to only Skr7.4 billion in that year, according to Statistics Sweden (SCB, 2017). These numbers clearly supported the idea of using a 'technology neutral' approach to internalize negative external effects over other approaches that attempted to select 'winners' through technology-specific 

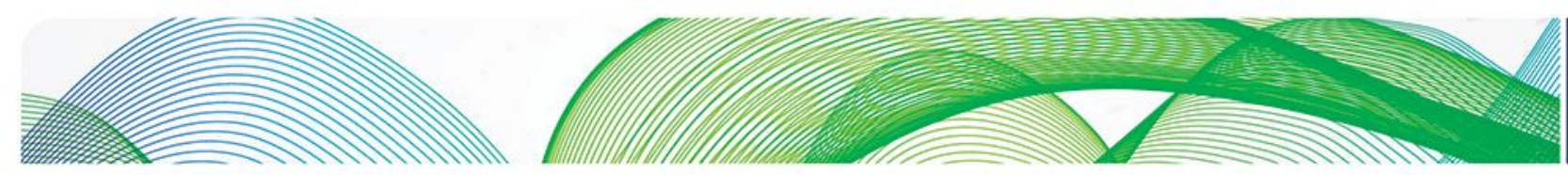

subsidy schemes. Furthermore, these numbers do not include the income transfer from consumers to producers of renewable energy through the green certificates scheme.

Sterner et al. (2013), also cited in the fifth IPCC assessment report, ${ }^{43}$ summarize the Swedish experience,

the $\mathrm{CO}_{2}$ tax seems to have had a major impact on fuels used for heating purposes, where biofuels and other non-fossil energy sources (such as energy from waste and surplus heat from industrial processes) have significantly increased their shares.

The Swedish National Institute of Economic Research (konjunkturinstitutet) in the annual environmental economic report (miljöekonomiska rapport) has regularly deemed carbon taxation to be a cost-efficient way to achieve, for example, the Swedish goal for the transport sector (National Institute of Economic Research, 2016).

According to the latest statistics from the International Energy Agency (IEA, 2017), the average Swede releases 3.86 tonnes of carbon dioxide $\left(\mathrm{CO}_{2}\right)$ per year into the atmosphere, compared with the EU average of 6.05 tonnes and the US average of 16.22 tonnes. Figure A1.2 illustrates the decline in the absolute level of greenhouse gas emissions in Sweden. ${ }^{44}$

Figure A1.2: Swedish greenhouse gas emission 1990-2015 in thousand tonnes excluding foreign transport and LULUCF

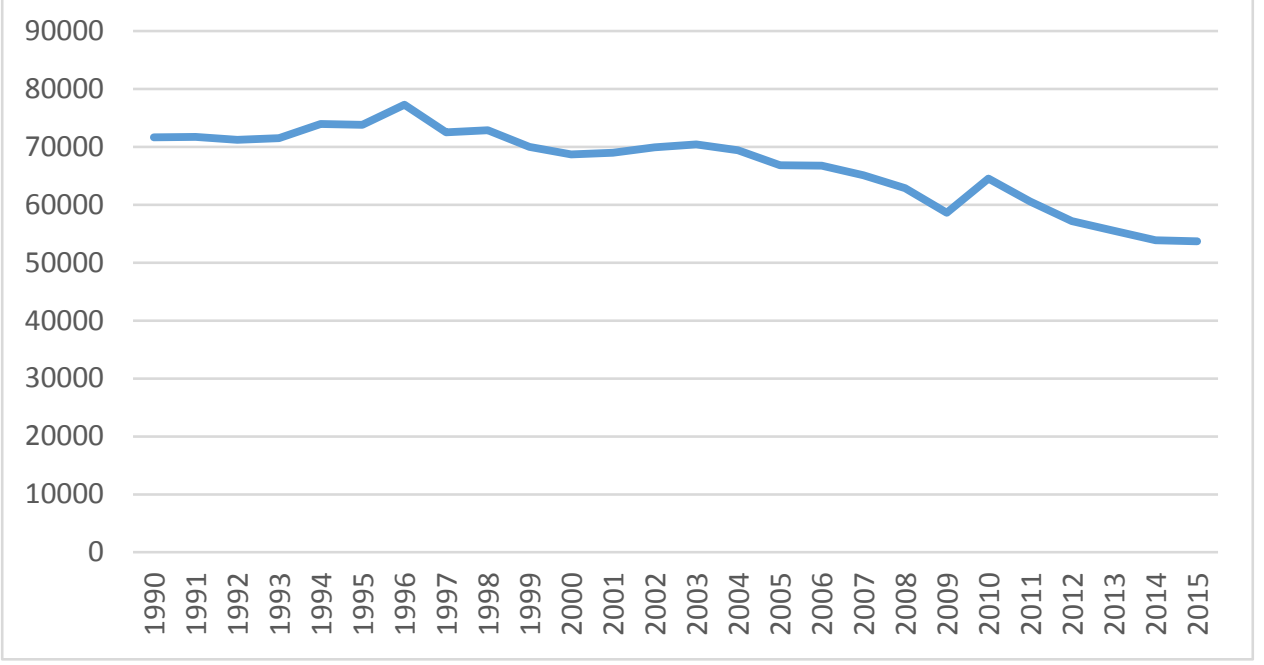

Source: (EPA), 2017).

In 2003 the Swedish green certificates scheme started. At that time, the European Commission was promoting support schemes for renewable energy and was favourable towards a market-based instrument. From the Swedish point of view, the certificates scheme had the advantage that it was financed off budget, at a time when Sweden was still concerned about reducing budget deficits and controlling government spending after the crisis in the middle of the 1990s. At the same time, the system fit well into the prevailing thinking that had led to the deregulation of the electricity market in 1996. An additional advantage of the system was its technology neutrality; all electricity produced from renewable sources was supported through the system, as opposed to earlier subsidy schemes that were financed through the budget and were technology specific.

\footnotetext{
${ }^{43}$ (IPCC 2014), giving a comprehensive survey on carbon taxation.

44 These data refer to emissions from fuel combustion.
} 

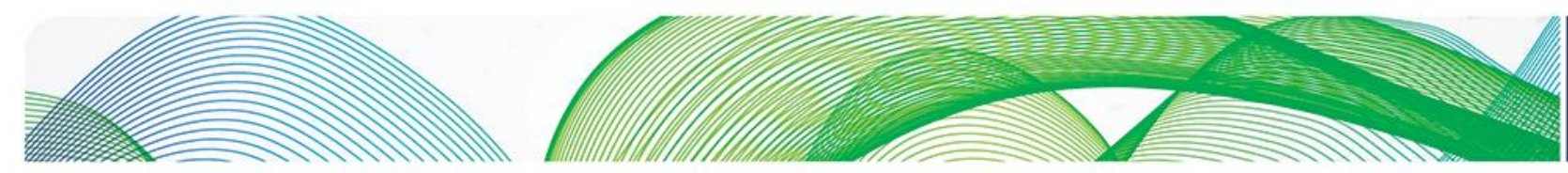

In 2016 the Parliamentary Energy Commission reached the so-called Energy Agreement that prolonged the green certificates scheme to 2030, increased it by an additional $18 \mathrm{TWh}$, and declared the aim for the electricity system to be 100 per cent renewable in 2040 . However, there was no decision for any future shut down of nuclear power. On the contrary, the agreement allows for the replacement of existing power plants with new plants - but without any government funding or subsidy. The agreement also stipulates the intention that Sweden continues to be a net exporter of large amounts of electricity. This implies that there will be enough electricity available in the near future for a continued electrification of the economy in the future

As is discussed in Vehmas (1999), environment-based taxation in the Nordic countries is part of sustainable energy policy in the region. Energy taxes in Sweden have encouraged investments in multifuel boilers in CHP. Tax differences between biofuels and fossil fuels led to biofuels being the first choice in new CHP and separate heating plants. Electricity production was not taxed. As is pointed out in Vehmas (1999) and confirmed by the IEA (2004), due to these tax differences, producers allocated biofuels to heating, and fossil fuels to tax-exempted (at that point) electricity generation. In addition to the tax exemption for biofuels, a subsidy for CHP plants has been available for CHP plant using biofuels.

Since 1 January 2004, special rules have applied to CHP. No energy tax and only 21 per cent of the carbon tax should be paid for fuels used for heat production in these plants. With the start of EU ETS, Sweden included district heating in that system for taxing $\mathrm{CO}_{2}$ emissions. As a consequence, the carbon tax was removed for CHP plants on 1 January 2013 by the centre-right government. However, it was reintroduced from 2016 by the government led by social democrats and the green party, because the effect of the EU ETS was deemed to be too weak.

Due to the introduction of the green certificates scheme, the trend towards biofuels continued because existing biofuel-driven heat production received electricity certificates for the electricity generated. As was pointed out above, Sweden has a well-developed district heating system which has a fossil fuel share of about 8 per cent, compared to 71 per cent in 1983 (Energimyndigheten, 2017a).

Carbon emissions in the heating sector in Sweden have decreased rapidly and today carbon emissions (Figure A1.3) from heating are low, due to the low carbon contents of the three major sources of heat: district heating, heat pumps, and solid biomass. Oil is responsible nowadays for less than 2 per cent of heating of dwellings and services (Energimyndigheten, 2017a). The policy instruments described above have clearly worked against fossil-based heating and made the alternatives more competitive. 

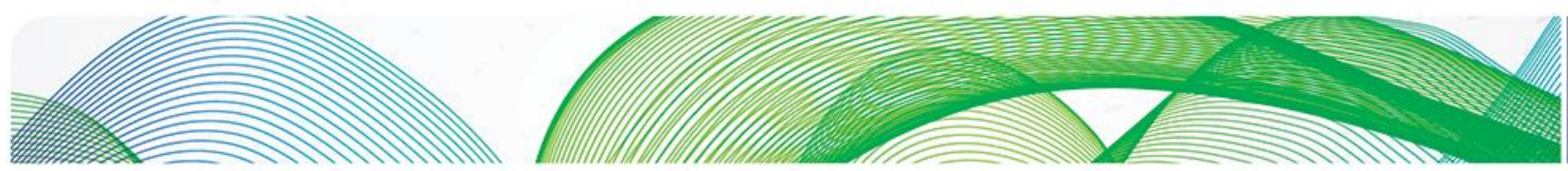

Figure A1.3: GHG-emissions from heating of dwellings and services 1990-2015 in 1000 ton $\mathrm{CO}_{2}$-ekv.

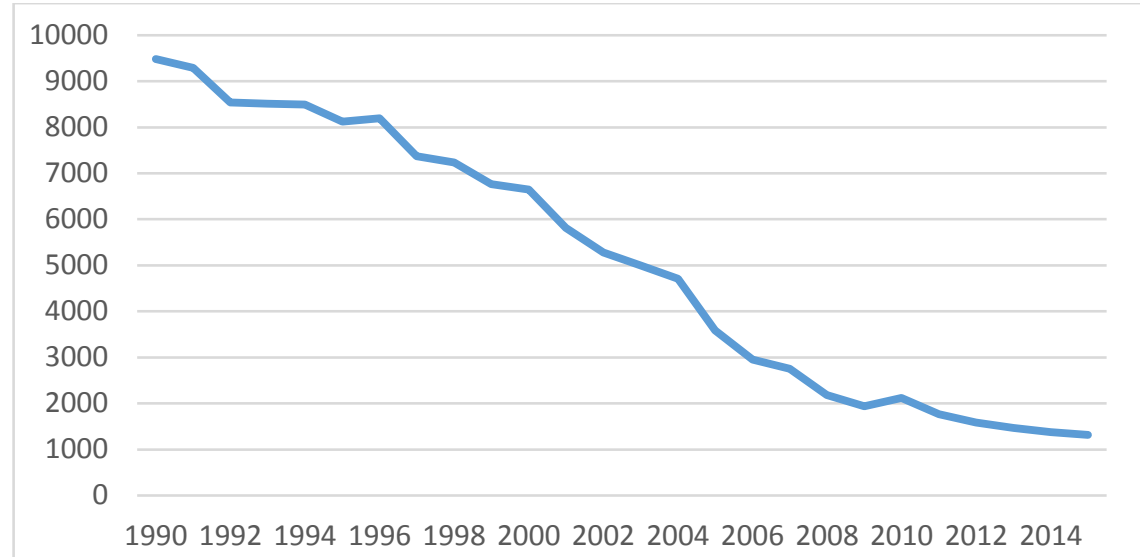

Source (EPA, 2017).

While district heating has had a successful past, its future looks dimmer both due to increasing competition from heat pumps and from decreasing energy demand for heating purposes (Werner, 2017). Diminished demand is largely due to the need to meet new European directives on energy efficiency and energy performance of buildings. In addition, the 2016 Swedish Energy Agreement stipulates an energy efficiency improvement of 50 per cent in 2030.

As shown in Error! Reference source not found., total GHG emissions from heat and power eneration have decreased significantly since 1990, in spite of growing heat and power demand during the same period. This was mostly a result of carbon and energy taxation, the green certificates scheme, and maybe even the EU ETS.

Figure A1.4: GHG emissions from heat and power generation since 1990 in 1000 ton $\mathrm{CO}_{2}$-ekv.

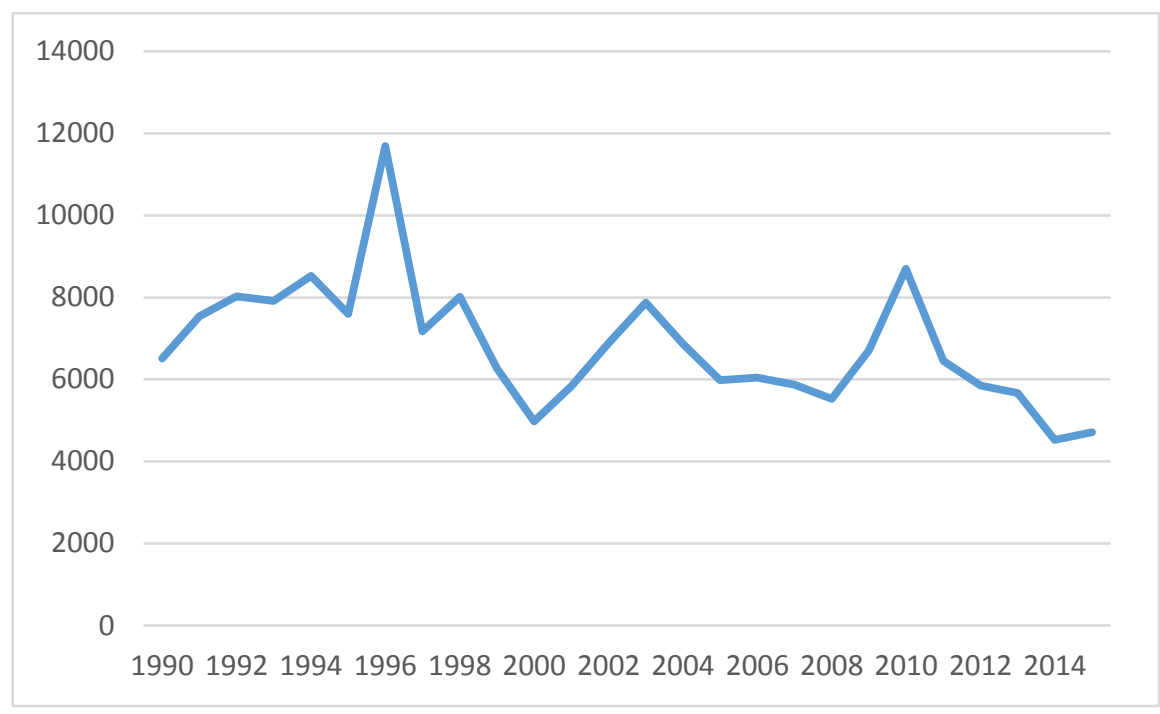

Source (EPA, 2017).

Until recently there has been no policy in place to support a transition to electric cars by supporting the infrastructure. The conversion of the transport sector, aiming at the goal of a fossil-fuel independent car 

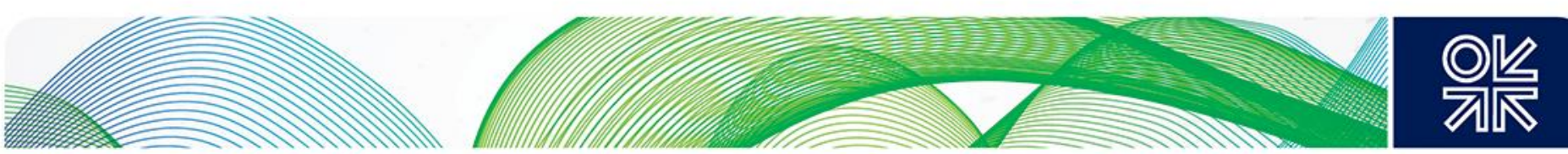

fleet by 2030,45 was mainly achieved by direct support schemes for cars with better environmental performance and by a tax exemption for biofuels. More recently, In 2015 the Swedish government started a new support scheme 'klimatklivet' (climate stride/leap) that also includes the subsidization of a charging infrastructure for cars in municipalities and in connection with multi-person dwellings. Furthermore a bonus-malus system is supposed to be implemented by 1 July 2018, subsidizing consumers who buy cars with low emissions, and punishing customers buying cars with high emissions ${ }^{46}$ The effects of such a system are, however, unclear. Furthermore the tax exemption for biofuels will be replaced by a quota system based on emission reductions.

Concluding, Sweden has found a way to combine lower carbon emissions with economic growth. On the one hand, the country benefits from favourable conditions for low-carbon power production and an early commitment to nuclear power. On the other hand, it has used powerful policy instruments to drive the increase of renewable power production and the decarbonization of the economy. The major problems left are the transport sector and parts of industry. But even here, solutions are being developed to achieve ambitious political goals and electricity will have an important role to play in the future.

\footnotetext{
${ }^{45}$ The meaning of 'fossil independence' was clarified by a parliamentary commission on environmental goals, (miljömålsberedningen SOU 2017:47) to mean a reduction of GHG emissions from the transport sector by $70 \%$ to 2030 .

${ }^{46}$ Ministry of Finance ((2017)
} 


\section{References}

Åberg, A. (2013). A gap in the grid - Attempts to introduce natural gas in Sweden 1967-1991, Stockholm: Doctoral thesis Historical Studies of Science Technology and environment.

Bosquet, B. (2000). 'Environmental tax reform: does it work? A survey of the empirical evidence', Ecological Economics, 34 (1), 19-32.

Brandel, M. (2001). Vattenkraften, staten och de politiska partierna, Stockholm: Nya Doxa.

Energimyndigheten (2017a). Energiindikatorer 2017, Eskilstuna.

Energimyndigheten (2017b). Energiläget i siffror 2017, Eskilstuna.

EPA (2017). Nationella utsläpp och upptag av växthusgaser (national emissions and absorption fo GHG), Environmental Protection Agency, (6th March), https://www.naturvardsverket.se/Sa-marmiljon/Statistik-A-O/Vaxthusgaser-nationella-utslapp-och-upptag-1990-2015/ from 15052017.

Helldner, M. T, et.al., (2008). Ågesta - kärnkraft som kulturarv, Helldner, M. T., Lundgren, P. and Rittsél, E. D., Tekniska Museet.

Högselius, P. et. al. (2007). När folkhemselen blev internationellt - elavregleringen i ett internationellt perspektiv. Högselius, P. and Kaijser, A. , SNS Förlag.

IEA (2004). Energy policies of IEA countries: Sweden 2004 review, OECD/IEA.

IEA (2017). CO2 emissions statistics, Hämtat från https://www.iea.org/statistics/topics/CO2emissions/ den 14072017

IPCC (2014). Climate Change 2014: Mitigation of Climate Change, Intergovernmental Panel on Climate Change.

Ministry of Finance (2017), Ett bonus-malus-system för nya lätta fordon, Fi2017/01469/S2

National Institute of Economic Research (2016). Miljöekonomisk rapport. Stockholm.

SCB (2017). http://www.scb.se, 'Miljöskatteintäkterna fortsätter att öka': www.scb.se/hitta-

statistik/statistik-efter-amne/miljo/miljoekonomi-och-hallbar-

utveckling/miljorakenskaper/pong/statistiknyhet/miliomotiverade-subventioner-och-preliminaramiljoskatter-2016/, 17052017.

Sohlmann, $\AA$ (2013), 'Energipolitiken', in Tarschys, D. and Lemne M., Vad Staten vill . mål och ambitioner i svensk politik, Gidlunds förlag.

SOU (1989). Ekonomiska styrmedel i miljöpolitiken. Delbetänkande fràn miljöavgiftsutredningen, 1989:83, Stockholm: Allmäna förlaget.

SOU (1989). Sätt värde pa miljön. Miljöavgifter pa svavel och klor Delbetänkande från miljöavgiftsutredningen, 1989:21, Stockholm: Allmänna förlaget.

SOU (1990). Sätt värde på miljön. Miljöavgifter och andra ekonomiska styrmedel. Slutbetänkande från miljöavgiftsutredningen, 1990:59, Stockholm: Allmänna förlaget.

SOU (1997). Skatter, miljö och sysselsättning, Slutbetänkande från Skatteväxlingskommittèn, 1997:11, Stockholm: Fritzes.

Sterner et al. (2013): 'Sweden's CO2 tax and taxation reform experiences', Thomas Sterner, Henrik Hammar, and Susanne Åkerfeldt, in R. P. Genevey, Reducing Inequalities: A Sustainable Development Challenge. TERI press.

Uba, K. (2010). 'Who formulates renewable energy policy?', A Swedish example', Energy Policy, 38, 6674-83. 

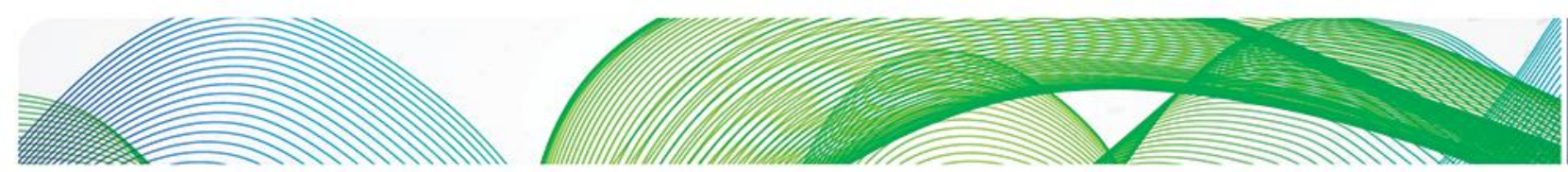

Vehmas, J. et al. (1999). 'Environmental taxes on fuel and electricity - some experiences from the Nordic countries', Jarmo Vehmas, Jari Kaivo-oja, Jyrki Luukkanen, and Pentti Malaska, Energy Policy, 27, 343-55.

Werner, S. (2017). 'District heating and Cooling in Sweden', Energy, 126, 419-29.

Ydersbond, I. M. (2014). 'Aiming to be environmental leaders, but struggling to go forwards: Sweden and Norway on Energy System transformation', Energy Procedia, 58, 16-23. 


\section{Annex 2: Decarbonization of heat in the UK and the role of 'green gas' - can economic instruments deliver? ${ }^{47}$}

\section{Introduction}

This Annex stems from a wider OIES project on the decarbonization of heat in Europe, but for the purposes of the present report it focuses on the extent to which fiscal policy can play a role in the decarbonization of heat in the specific circumstances of the UK. As discussed in the main report, decarbonization policies hitherto have mainly impacted the electricity sector, leading to unanticipated, and in many cases unintended, consequences. If Europe in general, and the UK in particular, are to meet their long-term goal of reducing emissions by at least 80 per cent by 2050 as compared with 1990, they will need soon to face a new set of challenges - the decarbonization of heat and transport. The implications for these sectors could be even more profound than those experienced by the electricity sector.

Natural gas has been relatively sheltered from the decarbonization process hitherto but, as the focus starts to turn to heat, this could change. Natural gas is the biggest single source of heat in Europe; conversely, heating is the largest single market for gas, so its future is closely intertwined with what happens in the heat sector. The possible range of outcomes is huge. On the one hand, gas could virtually disappear from this market; on the other hand, it is possible that demand for gas in heat could actually increase if the 'green gas' option develops effectively.

The issues have been studied most intensively in the UK, where the use of hydrogen as a replacement for natural gas in the heating sector has emerged as a serious option. The option has been shown to be technically (and probably economically) feasible, at least as compared with other low-carbon options. This report focuses on aspects which have so far received less attention, and in particular on the policy instruments which would be needed to deliver a switch to hydrogen.

\section{Background - decarbonization of heat in the UK}

The UK has a rigorous decarbonization framework, underpinned by the Climate Change Act 2008. This sets a binding target for the UK for the year 2050 (of an 80 per cent reduction in greenhouse emissions as compared with 1990 levels) and provides for the establishment of a trajectory to that goal based on five year 'carbon budgets' (in other words, a level of emissions to be achieved over each succeeding five year period). The budgets are also legally binding - the Secretary of State has a duty, first to set the budgets, then to ensure that emissions do not exceed that budget.

The framework has proved very successful - the UK has already achieved reductions in emissions of over 40 per cent. However, the future challenges are great. The UK budget for the period 2028-32 involves a 57 per cent reduction in emissions. To achieve that it will need to start making significant reductions in the residential heat sector, which has hitherto contributed little, and the Climate Change Committee has made it clear that emissions from the sector will need to be near zero in 2050 (CCC 2016).

\section{Why hydrogen?}

To understand why 'green gas' (in the form of hydrogen) is central to the UK debate, it is important to recognize some significant features of the UK energy landscape. In effect, it is composed of three separate sectors, each with its own fuel of choice:

- Electricity is mainly used (over 75 per cent) in applications where there is little competition, such as appliances, information and communications, lighting, and static motors.

- Heating is dominated by gas (about 80 per cent).

- Transport is more or less monopolized by oil (over 90 per cent).

\footnotetext{
${ }^{47}$ This annex was written by Malcolm Keay, Senior Research Fellow at the Oxford Institute for Energy Studies.
} 
This tripartite division is not just a matter of chance. The fuels each have qualities which make them well suited to the sector concerned; for people to change their energy source is not just a matter of changing from one sort of energy to another, but of changing the whole service in question.

Due to the dominance of gas in heating in the UK, there are few alternatives to the gas and electricity networks when it comes to options for the decarbonization of heat. There is very little district heating it supplies less than 2 per cent of UK heating demand (DECC 2013). While there is some scope for expansion, especially in new developments, retrofitting large areas is likely to be both prohibitively expensive and time consuming given the UK's urban architecture and preference for individual housing. Similarly with biomass heating, most commentators would agree that the potential is limited. Biomass makes up only 3 per cent of the UK's energy supply; there are major question marks over sustainability and environmental impacts (RIIA, 2017).

Energy efficiency will, of course, be a very important part of the overall strategy whichever route is followed; in particular it can help reduce investment costs. But energy efficiency on its own (without fuel switching) cannot meet the emissions reduction targets. Achieving such targets would require replacing the entire UK building stock within a few decades. However, the completion of even small-scale developments of low-carbon housing have proved very difficult, while the investment requirements for a full-scale retrofitting of the UK's old and inefficient housing stock (putting it onto a zero-carbon basis) would be prohibitive.

When it comes to the electricity option, there are major challenges. As the main report discusses, peak heat demand is very much higher (about six times) than peak electricity demand and heat demand is much more variable across the year. Meeting heat demand directly by electricity would impose enormous strains on the system. The problems could be mitigated by the use of heat pumps - these can achieve levels of efficiency, as measured by their coefficient of performance, of 3:1 or even more, reducing the input energy requirement considerably. With better levels of insulation reducing the energy required even further, the increase in demand might be limited to perhaps twice the current electricity peak levels (Eyre and Baruah 2015), but even then it would be a major challenge.

Furthermore, in addition to the cost implications of the heat pumps and insulation required, it is likely that there would be significant changes in the consumer experience. Heat pumps tend to deliver energy slowly and steadily, and may not be able to adjust their output in response to a sudden cooling of the external temperature (when their own efficiency tends to be at the lowest in any event). Consumers may therefore resort to other means of boosting peak heat delivery, adding to the cost and practical difficulties and, potentially, to emissions.

In practice, attempts to encourage the use of heat pumps in the UK have hitherto proved largely unsuccessful; apart from the change in the consumer experience, there are issues with the high initial cost and the lack of consumer benefit. While it might be possible to provide stronger incentives to increase their attractiveness for consumers, this would be likely only to encourage take-up of the technology by those with existing electric heating; given the extra cost and the loss of convenience, it is very difficult to see how consumers could be persuaded to change from gas heating.

\section{Storage}

Furthermore there is a huge storage issue with any electricity-based option, arising from the variability of heat demand. The electricity industry is already encountering major problems in balancing supply and demand because of the penetration of intermittent sources. Periods without significant amounts of wind in the UK can be relatively extended (say ten days to a fortnight) even in winter at times of peak demand. Adding an enormous and highly peaky new form of demand would be likely to impose intolerable strains. One reason why gas dominates heating in the UK is the relative ease of storage at least in comparison with electricity. While it is true that significant strides are being taken in improving electricity storage via batteries and the like, it still remains very expensive and relatively small in scale. Battery storage generally costs over $\$ 200 / \mathrm{kWh}$ to establish currently, and the industry is aiming for its 'Holy Grail' of $\$ 100 / \mathrm{kWh}$. Meanwhile, gas storage in, say, salt caverns costs about $30 \mathrm{cents} / \mathrm{kWh}$ to develop (ERP, 2011) and short-term gas storage via 'linepack' is even cheaper. Another benchmark is 
that the UK's capacity for electricity storage (mainly in pumped storage) is less than $30 \mathrm{GWh}$ - perhaps an hour's worth of demand. The country has nearly 50 TWh of gas storage - over 1,500 times as much (ERP 2011).

\section{The hydrogen option}

Meanwhile, as the problems with the electricity option become more apparent, options involving the use of the gas network start to look more attractive, as reflected in a flurry of recent publications (Green Gas, 2016; KPMG, 2016; MacLean et al., 2016; Policy Exchange, 2016; H21, 2016, among others). Although in principle there could be a number of options - including biogas, synthetic natural gas, or hydrogen from electrolysis - in practice, the use of steam reforming to convert methane to hydrogen, and allowing the $\mathrm{CO}_{2}$ generated to be sequestered using Carbon Capture and Storage (CCS) technology, has emerged as the front-runner.

It is not the purpose of this report to examine this option in detail. As noted above, a number of recent papers have considered it from a technical and economic perspective, and these studies are, in a sense, the starting point for this report - they have taken the issue far enough to show that it could be a technically feasible alternative.

One of the most significant of these studies is the so-called ' $\mathrm{H} 21$ ' project $(\mathrm{H} 21,2016)$ which undertook a detailed examination of a particular city (Leeds in the north of England) to see if it would be practical to convert it to hydrogen. The study looked at such issues as pipeline safety and capacity, broad cost estimates, and the availability of CCS technology and storage sites to see if the option was broadly feasible and concluded that it would be.

The study is not necessarily relevant to other European countries. The UK has a number of specific features, including the following:

- It is in the process of converting its distribution system to polythene pipes, which can carry hydrogen with little or no technical adjustment - avoiding the issue of 'embrittlement' which limits the volume of hydrogen that can be carried through traditional metal pipes.

- Distribution systems in the UK have sufficient capacity to meet demand with relatively little modification, despite the fact that hydrogen has a lower calorific value than methane. This is partly because, in many cases, the systems were developed to distribute 'town gas' (manufactured from coal) which also has a lower calorific value than natural gas.

- Although transmission lines would need to be converted to carry hydrogen, distances within the UK are relatively short and the costs are not prohibitive.

- As a longstanding gas producer, the UK has a number of coastal terminals where steam reformers could be sited. These locations would be convenient both for the availability of gas for reforming and for access to depleted offshore fields for carbon storage.

The evidence from this and the other studies referenced suggests that the gas-to-hydrogen option has a number of positive features, including:

- Minimizing change in the consumer experience - they could still use cooking facilities and central heating via hot water boilers as at present. The changeover to greener gas would involve disruption but of a manageable sort - broadly similar to that involved in the switch to North Sea gas from town gas which took place in the UK in the 1970s.

- The acceptability of a switch to hydrogen is problematic but it also seems manageable. No doubt there would need to be a major campaign to persuade consumers of hydrogen safety. However, town gas in the UK was a mixture of hydrogen and carbon monoxide. Using hydrogen on its own would actually raise fewer safety issues.

- The environmental advantages of a switch to hydrogen from methane are real, though they would need to be examined in more detail to establish how they compare with electrification options. CCS generally manages to capture only 80-90 per cent of emissions.

- The economics of the approach cannot be definitively considered until full-scale demonstrations of hydrogen supply and CCS have been undertaken. Nonetheless, the studies referenced suggest that the costs of this option could be significantly lower than the electrification option once 
the relevant storage and other costs, and the cost of upgrading the housing stock, are taken into account.

- It minimizes the problem of stranded assets. Natural gas production as such is a naturally declining asset - it should be possible to phase it out gradually with the introduction of alternative sources. But the gas pipeline system is a huge and long-lived asset and, whatever the source of hydrogen, use of this asset is likely to reduce new infrastructure costs.

- There are potential synergies with the electricity sector; for example a switch to hydrogen could make it possible to store electricity indirectly by converting surplus power to hydrogen via electrolysis, then using it for heat generation or even transport (via fuel cells) in a hydrogen economy.

\section{Policy feasibility}

At the very least, the studies therefore suggest that on technical and economic grounds it is worth giving serious consideration to the 'green gas' option of converting methane to hydrogen, and it is not the purpose of this report to revisit these issues; rather it will take it for granted that the prima facie case is there and proceed to ask how we might map out a route to this potential destination. In particular, this Annex looks at policy instruments which might deliver a decarbonized heating system based on hydrogen.

It may first be worth considering why pure economic instruments were not used to promote the growth of renewables in electricity. Many economists would argue for a carbon tax or trading scheme as the most efficient mechanism to promote decarbonization, yet the main policy choices for renewables in Europe have been Feed-In Tariffs and Renewables Obligations. The present author has looked in more detail elsewhere at the reasons why carbon pricing was not the main policy of choice (OIES 2016, Chapter 8); the reasons are summarized below. Ultimately, the problem stems from a fundamental mismatch - relying on markets and market forces means accepting market outcomes, but environmental targets are nearly always expressed in terms of specific policy-favoured outcomes, in terms of the share of renewables or emissions reduction (rather than, say, in terms of addressing a market failure by incorporating the relevant externalities).

This starting point entails fundamental strains, of which the following are examples:

- Credibility It is very difficult to make a carbon tax credible over a long enough term to act as a basis for investment. A new nuclear station, for instance, might take a decade to build then operate for a further four or five decades or more.

- Political issues Part of the problem is the inherent political sensitivity of taxation and the difficulty of reaching agreement at international level. There is a tendency to go for the lowest common denominator. Many countries will simply not accept a scheme which will generate a tax high enough to have a significant impact on investment.

- Consumer acceptability In principle, a carbon tax may be a low-cost way of achieving a decarbonization objective. In practice, however, taxes are highly visible and unpopular with consumers. It is true that at present those same consumers bear the cost of renewables support in other ways - and at well over $€ 100$ per tonne of carbon, this is much higher than any conceivable carbon tax (OIES, 2016). Nonetheless, the cost is in general hidden within the electricity bill and, because of the confusing nature of the public debate about the cost of renewables (OIES, 2013), consumers often have little idea of the cost burden involved.

- Mitigating risk Renewables are in general very capital intensive; a major component in cost reduction is therefore reducing the cost of capital by reducing risk, for example by guaranteeing offtake volumes and prices. This consideration was important in motivating the shift from the Renewables Obligation to Feed-In Tariffs in the UK.

- Technology development The cost of renewables has fallen very substantially over time and there can be no doubt that the degree of government support given to the technologies has contributed significantly to this process. Experience suggests that the main cost reductions come from the learning effects and economies of scale which are encouraged by significant deployment. 
In other words, there have been strong reasons for governments to rely on specific instruments, rather than on an overall carbon tax or cap, in their efforts to promote renewables in electricity.

Do similar arguments apply in relation to hydrogen for heating? Unfortunately (at least in the view of this author) the arguments for a significant degree of central direction appear even stronger in this connection. In addition to the factors mentioned above, they include the following:

- Competition The relative lack of competition in the main applications of electricity has facilitated the 'electricity first' approach. With gas, the position is more complex. While gas dominates the heating market, it does face potential competition from other sources; more significantly hydrogen, if it were delivered as a separate option, would face competition from natural gas unless the government arranged measures to avoid this. For the consumer, there is no advantage, and considerable cost, in a switch to hydrogen. It is difficult to estimate the full impact of the additional costs involved, but there are detailed calculations in $\mathrm{H} 21$ (2016) which produce an estimate of around $7 \mathrm{p} / \mathrm{kWh}$ for delivered hydrogen. This compares unfavourably with today's gas prices (less than $3 \mathrm{p} / \mathrm{kWh}$ ) although it is broadly competitive with electricity (at around $12 \mathrm{p} / \mathrm{kWh}$ - though electricity has potentially higher efficiencies and flexibility in use).

- Network issues A key difference between hydrogen and renewables is that hydrogen would ultimately require a dedicated network. Renewables produce electricity which is indistinguishable at the consumer end, and within the transportation system, from other sources. This enables the cost to be 'socialized' (in other words, to be spread across all consumers) in a straightforward (and largely hidden) fashion. With hydrogen such 'socialization' of the cost is limited by the technical issues. To achieve significant emissions reductions, a hydrogen-only system would be needed; it would not then be possible for individual consumers to choose hydrogen or methane or consume a blended product - the local network would have to carry one commodity only.

- Coordination issues The problem of coordination might seem highly technical but in fact could be fundamental to the development of a hydrogen system. The gas chain is complex - producers, transporters, aggregators, suppliers, and consumers. For hydrogen to develop, each link would have to see a benefit and coordinate their activities accordingly. Furthermore, there would be additional links in the chain such as: methane reformers, carbon capture, transport and storage, and consumer appliance conversion. With renewables in electricity the problem is largely upstream and confined within a single jurisdiction; it is relatively easy to impose renewables obligations, or to require suppliers to buy renewables on Feed-In Tariffs. With gas, by contrast, producers are often extra-territorial and they may see no advantage in supplying gas for hydrogen manufacture; consumers, similarly, may see no benefit for themselves in a switch to hydrogen. Yet all would have to move together for a hydrogen system to develop. It appears to be primarily coordination issues of this sort - getting the incentives of all parties aligned, and the risks mitigated - which have so far slowed down the development of CCS. The extra problems with hydrogen are only likely to compound the difficulties.

- Equity With electricity, as noted above, the costs of decarbonization have been socialized. Since this has applied equally to all suppliers and consumers it has been broadly compatible with both equity and continuing competition between suppliers. It is difficult to see how this approach could be adopted with the development of hydrogen networks. As discussed above, it would not be practicable to convert the entire country overnight - instead, an area-by-area approach would need to be adopted, as set out in the H21 Report, and as was the case with the conversion to North Sea gas in the 1970s. But the cost of hydrogen in the areas converted would be very much higher than the cost of the gas that was previously available to consumers. It would not be equitable for consumers in one part of the country to pay a much higher price than those in another region simply because they happened to be first in line for the new network. Similarly, it would not make for a level and competitive playing field if some suppliers happened to have a larger presence in that area than others. Some way would have to be found of socializing the costs across the rest of the gas network, so that even those consumers who were not using hydrogen were bearing a fair share of the costs. This would be much more visible politically, and much more problematic for competition, than the socialization of renewables costs.

- Need for a long-term strategy In the situation envisaged, there would be no market signals to optimize system development (such issues as: deciding which areas to convert first; what new pipelines would need to be built; where to store the carbon generated; whether to convert the 
whole gas system or only metropolitan areas; and whether industry should be allowed to continue with a separate natural gas supply). The long-term strategy would need to be decided centrally, communicated clearly, and delivered in a systematic way. Regulation of pipelines and final markets would need to be consistent with the overall objective. This would imply central planning and coordination of a sort which could be incompatible with liberalized markets.

All this means that it is very difficult to see how fiscal policy on its own could deliver decarbonization of heat via any of the main routes identified to date in the UK. Extensive direct intervention in the market would be needed for hydrogen to develop. Any of the other options on the table - extension of heat networks or of biomass, for instance - would require even more active government direction given that they are, on the face of it, less attractive than the hydrogen option.

The only major qualifications are: first, that time may alter things - higher gas prices and carbon taxes could change the relative attractiveness of gas heating, while cost reductions in renewable electricity, electricity storage, steam reforming, or CCS might narrow the gap between gas and the low-carbon options. But that requires a heroic set of optimistic assumptions, given the size of the gap to be bridged. The second qualification is that a first step might be to blend hydrogen into the existing gas system. That would avoid many of the issues listed above - it would be broadly similar to the promotion of renewables in electricity (though of course that has had huge impacts). It would also reduce emissions (but by well under 10 per cent given the technical constraints and the low calorific value of hydrogen) and might be regarded as a preliminary step in establishing the viability of the steam reforming/CCS option. However, it would not of itself be anything like sufficient to meet the long-term target and could be regarded as an expensive diversion.

\section{Conclusions}

For the reasons given above, the difficulties of relying on market forces and fiscal signals in relation to the decarbonization of heat via hydrogen are even greater than with electricity, and might ultimately be incompatible with any sort of liberalized market. Indeed, in the view of the present author, this might be an even more significant barrier to the development of this option than the economic and technical considerations. Governments are unlikely to resort to a sufficient degree of intervention unless convinced that there is really no alternative.

This does not mean that fiscal policy has no role in relation to the decarbonization of heat - as discussed in the main report, a rebalancing of the fiscal burden, which is at present borne almost exclusively by electricity consumers, would help create a level playing field. In particular, it might help the relative attractiveness of the heat pump alternative - though not by enough to make that option attractive other than to those currently using electricity for heating. So, in the UK at any rate, it is likely that, as with electricity, the role of fiscal policy in relation to the decarbonization of heat will be ancillary rather than central. Some distortions could certainly be removed by a rebalancing of fiscal policy, but that would not on its own deliver the scale of emissions reductions to which politicians are committed. 


\section{References}

CCC (2016). 'Next steps for UK heat policy Committee on Climate Change', Committee on Climate Change, October 2016.

DECC (2013). 'The Future of Heating: Meeting the Challenge', Department of Energy and Climate Change, Policy Paper, March 2013.

ERP (2011). 'The future role for energy storage in the UK', Energy Research Partnership, June 2011.

Eyre and Baruah (2015). 'Uncertainties in future energy demand in UK residential heating', Eyre, N. and Baruah P., Energy Policy 87 (2015) 641-53.

Green Gas (2016). 'The Green Gas Book', Parliamentary Labour Party Energy and Climate Change Committee, London Summer 2016.

H21 (2016). 'H21', Leeds City Gate Project, Northern Gas Networks 2016.

KPMG (2016). '2050 Energy Scenarios: the UK gas network's role in a 2050 whole energy system', KPMG, July 2016.

MacLean et al. (2016). 'Managing Heat System Decarbonisation', MacLean, K., Sanson, R., Watson, T., and Gross, R., Imperial College, London April 2016.

OIES (2013). 'Renewable Energy Targets: the importance of system and resource costs', Keay M., Oxford Energy Comment, OIES, February 2013.

OIES (2016). Europe's Long Energy Journey: towards an energy union?, Buchan D. and Keay M., Oxford University Press/Oxford Institute for Energy Studies, 2016.

Policy Exchange (2016). 'Too hot to handle: how to decarbonise domestic heating', Policy Exchange, London 2016.

RIIA (2017). 'Woody Biomass for Power and Heat: Impacts on the Global Climate', Royal Institute for International Affairs, February 2017. 